\title{
MASS FLOW AND PARTICLE SIZE MONITORING OF PULVERISED FUEL VERTICAL SPINDLE MILLS
}

\author{
Hamresin Archary ${ }^{*}$, Walter Schmitz ${ }^{2}$, Louis Jestin ${ }^{3}$ \\ ${ }^{1}$ Eskom Holdings SOC Ltd., South Africa \\ ${ }^{2}$ University of the Witwatersrand, South Africa \\ ${ }^{3}$ University of Cape Town, South Africa
}

\begin{abstract}
The first step towards condition based maintenance of the milling plant is the implementation of online condition monitoring of the mill. The following paper presents and analyses methods of monitoring the key performance factors of a vertical spindle mill that is suited for implementation on older power stations, i.e. the quantity (mass flow rate) and quality (particle fineness) of the pulverised fuel produced by the mill. It is shown herein that the mill throughput can be monitored on-line using a simple mill energy balance that successfully predicts the coal throughput within $2.33 \%$ as compared to a calibrated coal feeder. A sensitivity analysis reveals that the coal moisture is a critical measurement for this method to be adopted as an on-line mass flow monitoring tool. A laser based particle size analyser tool was tested for use in the power plant environment as an online monitoring solution to measure pulverised fuel fineness. It was revealed that several factors around the set-up and operation of the instrument have an influence on the perceived results. Although the instrument showed good precision and repeatability of results, these factors must be taken into account in order to improve the accuracy of the reported results before the instrument can be commissioned as an on-line monitoring solution.
\end{abstract}

Keywords: mill, pulveriser, on-line, condition, monitoring

\section{INTRODUCTION}

Coal fired power stations, even with the recent drive towards cleaner fuels, remain the most widely used and cost effective solution in power generation worldwide. Coal as a fuel, however, has many process related challenges that engineers have to contend with. These include the pre-processing (grinding and drying) and post-processing (de-dusting and ash removal) of the fuel. The coal milling plant is responsible for the pre-processing and thus serves two major roles, to prepare fuel and feed it to the furnace for combustion.

The preparation process entails the grinding and drying of raw coal into Pulverised Fuel (PF) of the correct particle size specification in order to ensure both stable and complete combustion in the furnace. Besides the effect on combustion efficiency, without accurate control of air and coal flow to each burner, technologies such as low $\mathrm{NO}_{\mathrm{x}}$ burners become ineffective.

The second role of the mill is to feed the required mass flow of coal to the furnace. One of the problems facing South African power stations is the deteriorating Calorific Value (CV) of coals burned for local consumption. This means that mills must operate close to the maximum designed throughput capacity in order to achieve the required increased mass flow of coal. Operating mills at such increased 
throughput requires that the mill is in good mechanical condition in order to achieve the correct particle fineness.

This emphasises the importance of maintaining proper control and good health of the milling plant. Milling plant maintenance and monitoring however, is currently performed on a time and failure based system. With the advent of on-line monitoring systems in the power station environment it has recently become possible to shift towards condition based maintenance of the milling plant. There are however, three prerequisites which must be met. In order to implement a condition based maintenance plan, one must first understand clearly, the dynamics of the system that govern the operation of a milling plant. Then the mill must be instrumented with performance monitoring equipment for both 'current status' monitoring as well as historical data acquisition. Finally, the interpretation of this data, in conjunction with tools such as mass and energy balances, will allow the determination of the health of the mill or specific components of the mill. By understanding the milling system, monitoring its key performance parameters and interpreting the resulting data, a mill condition monitoring system can be developed thereby paving the way for a condition based maintenance strategy to be implemented. Condition based maintenance begins with both good understanding and good condition monitoring of the system.

This paper describes the first steps towards implementing such a system and will focus on two key topics of the similarly titled research project. It will first be shown that the coal mass flow can be accurately predicted using an on-line mill energy balance. Furthermore, a laser based on-line Particle Size Analyser will be tested for use in the power station environment. Together these two on-line measurement and monitoring solutions will pave the way for real time condition monitoring of the two key performance parameters of a vertical spindle mill, (i.e. Throughput and Particle Fineness).

\section{MILL ENERGY BALANCE (MEB)}

\subsection{Mill energy balance outline}

The coal mass flow has been determined by means of a mill energy balance in conjunction with on-line input data. The exemplary mill in Fig.1 below is the 6M75E of FPM S.A. The milling plant consists of multiple key components. The mill body itself, which will form the boundary of the energy balance, is fed by the following auxiliary components at various points.
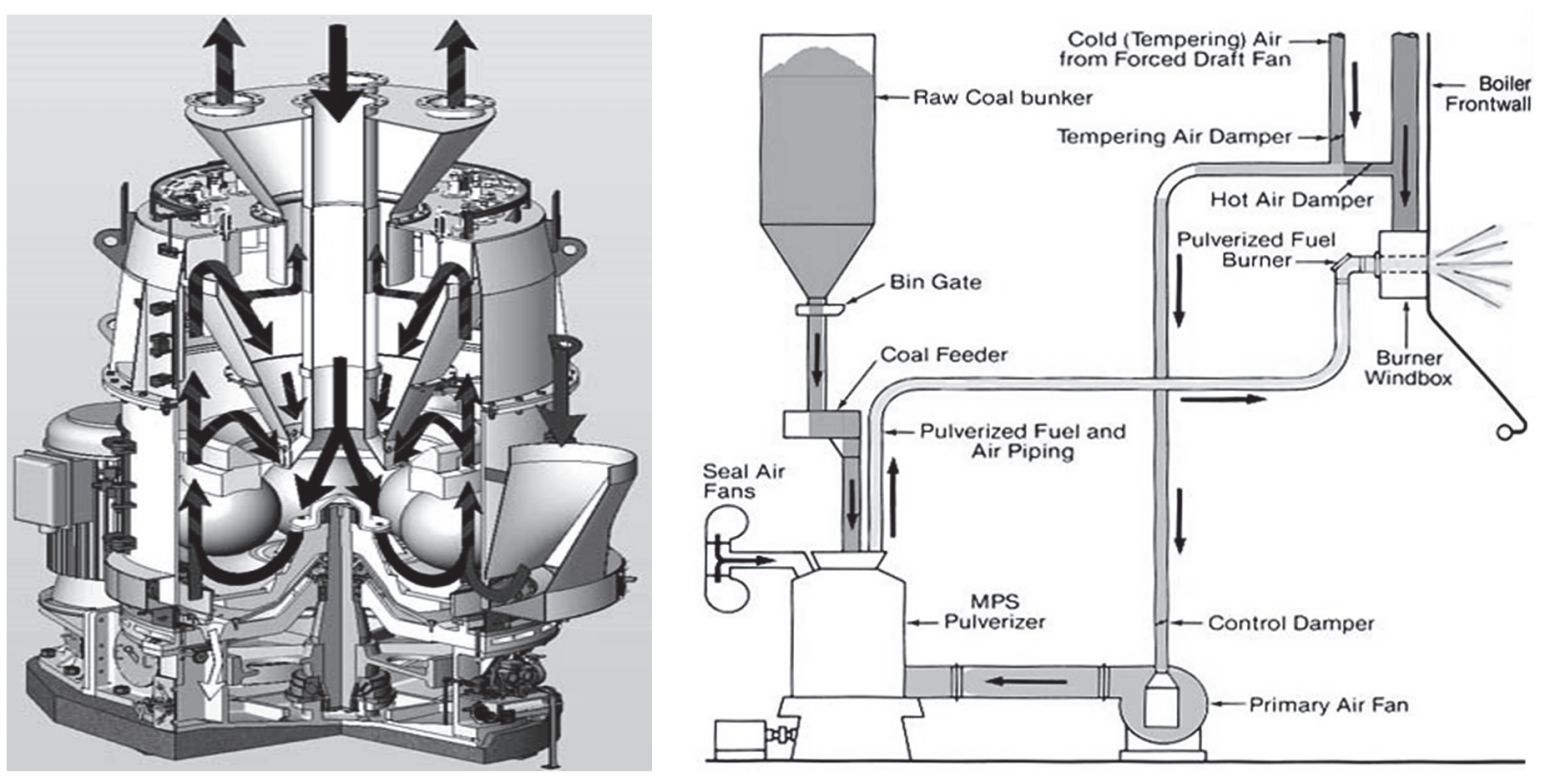

Fig. 1. Mill internal flows and process flow (FPM S.A., n.d.) (Kitto and Stultz, 2005) 
Hot primary air blows upward through the mill from the PA fan. Raw coal is fed into the mill from the coal feeder above it. The mill motor supplies energy to the mill by rotating the mill table and thus crushing the raw coal between the grinding elements. Furthermore there is a seal air fan which supplies sealing air to the bearings and labyrinth seals at various points across the mill body.

The primary air fan extracts air, from the secondary air duct, which has been heated via the air heater. A tempering air damper regulates the primary air temperature which is measured after the PA fan near the mill inlet. The coal flow is regulated in the control system by measuring the rotational speed of the screw feeder and applying a feed factor that is derived when calibrating the feeder. The measurement is volumetric and does not respond to changes in coal moisture or density.

The energy balance will solve for the coal flow and be compared to the calibrated feeder value for verification. The moisture contained in the air and coal has a large effect on the energy transfer inside the mill. The mill is controlled to evaporate the moisture contained in the coal and, as it is a sealed system, adds it to the gas stream at the mill outlet. The mill outlet stream is therefore made up of a mixture of pulverised fuel, primary air, seal air, and water vapour.

In order to simplify the model and overcome parameters that are difficult to measure in a real time manner, certain assumptions had to be made. The mill is said to be in steady state such that the inlet and outlet coal mass flows are equal. It is also assumed that heat loss through the walls of the mill is mainly due to convective heat transfer. As the mills that were modelled are exposed to a constant air flow at ground level, the effects of radiation and conduction heat transfer mechanisms are considered negligible in comparison. It is further assumed that the moisture contained in the coal is evaporated inside the mill. At an altitude of $1668 \mathrm{~m}$ above sea level the atmospheric pressure is approximately 83 $\mathrm{kPa}$. This means that the mill outlet temperature set point of $90^{\circ} \mathrm{C}$ is close enough to the vaporisation temperature of water at that pressure. It is also assumed that all seal air at sealing points enter the mill and contribute to the outlet flow. The total seal air mass flow is considered small in comparison to the total primary air flow. Finally the power that the mill motor draws is assumed to go directly into the grinding process as the mill table is rotated. There is a slight loss of energy through the mill gearbox which has an efficiency of $94 \%$.

\subsection{Literature review}

In the field of milling plant condition monitoring, Makokha et al. (2009) had shown that the mill outlet temperature and the pressure drop of a tube mill can be predicted by means of an energy balance model. The aim was to eventually incorporate the steady state model into the overall mill control scheme as an auxiliary monitoring tool for early detection of parameter drifts or malfunctions specific to tube mills. This is achieved by performing the calculation of the energy balance model, and comparing the expected values to those measured on the plant. From Fig. 2 it is seen that the model predicts the mill outlet temperature fairly well for mill loads below $80 \%$. At loads higher than $80 \%$ the model tends to underpredict the temperature by no more than $5 \%$. It must be noted that this model was developed specifically for a tube type mill which is significantly different to the operation of a vertical spindle mill. The success of the model in predicting the mill outlet temperature and the mill differential pressure is promising in light of the task set out herein, i.e. to predict the mass flow of coal using an energy balance model.

The model of Makokha et al. (2009) was implemented in such a way that it shadows alongside the control system playing an auxiliary monitoring role and purely provides advisory information to the operator. That concept was developed a step further when Fan and Rees (1997) implemented their own model in such a way that it not only monitors the process and provides advice to the operator, but is also able to intervene in the control system. This model performs on-line parameter estimation and performance prediction and uses experience based knowledge to perform fault diagnosis and prognosis 
and even proposed the optimal corrective action. The second function of what they term the Knowledge Based mill Operator Support/control System (KBOSS) allows it to perform mill and fuel supervision and control. This monitors the unit fuel demand and controls the mill load sharing coefficients thereby varying the loads between mills based on grinding element wear, in order to maintain the overall unit energy input.
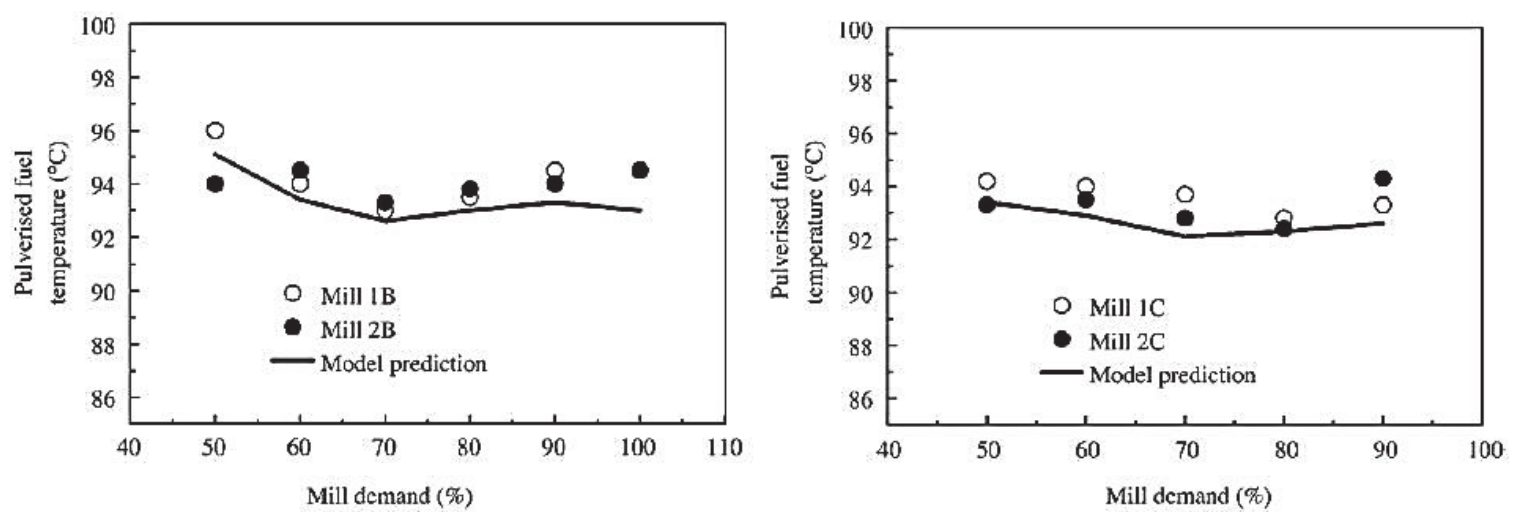

Fig. 2. Prediction of mill outlet temperature (Makokha et al., 2009)

Niemczyk et al. (2012) derived a mathematical coal mill model for control with the aim of providing better load following capabilities of pulverised fuel mills and thus of pulverised fuel fired power stations. The need for better load following capabilities has stemmed from the shift towards reduced power station emissions and new build projects based on renewable energy sources. This poses the problem of fluctuating load on the grid which base load coal fired power stations are forced to compensate for. An important bottleneck in the operation of coal fired power stations is the coal pulverisation process which gives rise to slow ramp-up rates and frequent plant shut downs (Rees and Fan, 2003). The paper explains that model based control of the milling plant has seen slow development due to the fact that the pulverised fuel leaving the mill had not been measureable in any real time manner. This is mainly as a result of the harsh and abrasive nature of pulverised fuel flow at the mill outlet.

An observer based fault detection and moisture estimation system was presented by Odgaard and Mataji (2007) by means of a simple mill energy balance. The term "fault" refers to what is commonly known as a coal hang up in the raw coal chute at the inlet to the mill feeder. A very simple energy balance model is used to determine the coal moisture and detect a fault as soon as it occurs. While Odgaard and Mataji (2007) have developed an energy balance that can predict the steady state operational moisture content of coal, they go on to refer to the prediction as a "noisy measurement". Despite this, the prediction followed measurement data very well as shown in Fig. 3.

The paper further emphasises, as was mentioned by Niemczyk et al. (2012) that the mass flow rate of coal out of the mill is an important variable that at the time was not possible to measure. This is important, as the focus of the energy balance that will be developed in this paper, is to predict the coal mass flow through the mill.

Mill energy balance models and observer based mill monitoring systems have to date lacked vital measurement parameters as model inputs, thus limiting their use in true condition based monitoring and maintenance systems. The Knowledge Based mill Operator Support/control System (KBOSS) in the paper of Fan and Rees (1997), had come the closest to achieving a true mill condition monitoring system. It combined on-line measurement and monitoring, mathematical modelling, as well as experience based knowledge to systematically identify common milling plant problems and even propose solutions to the operator. However, the technology available to them did not allow accurate and on-line measurement of pulverised fuel mass flow, or PF particle size for that matter, leaving the mill. 

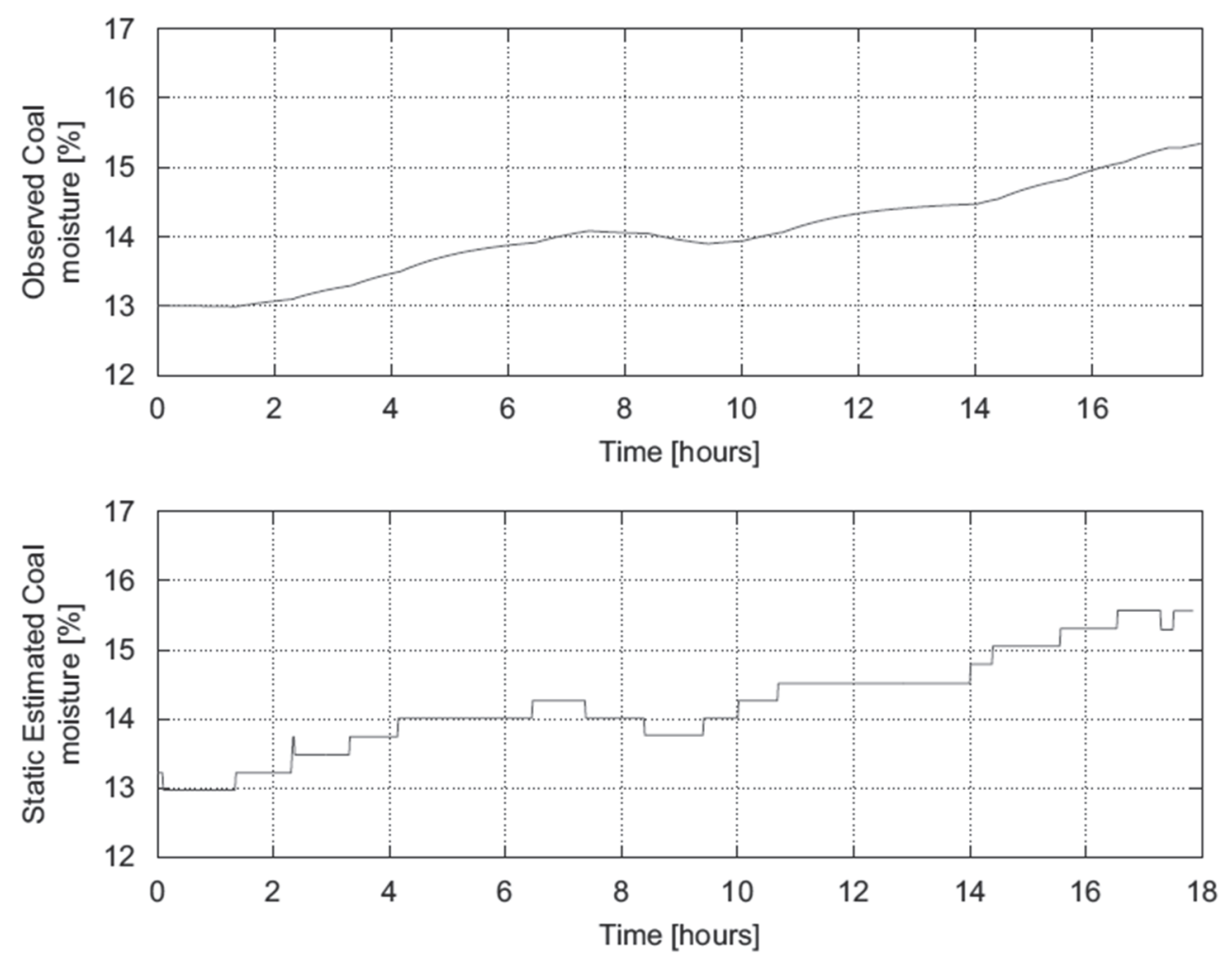

Fig. 3. Moisture estimation compared to measured values (Odgaard and Mataji, 2007)

Extensive work to build a multi-segment model of the milling plant was performed by Wei et al. (2007). The model consists of six segments that apply to different operating regimes of the mill. These are made up of start-up, standard milling, shut down, and transition periods in between. The model uses internal variables that reveal the characteristics of some un-measurable intermediate variables. These include the mass of coal in the mill, the mass of pulverised coal in the mill and the mass flow of pulverised coal out of the mill. It is noted that in this model the heat loss through the walls of the mill is assumed to be zero.

By indication of publications, interest has been poor in regard to monitoring of coal mills with the intent to perform fault and malfunction detections. Examples of such monitoring systems are those of Fan and Rees (1997), Makokha et al. (2009) and Odgaard and Mataji (2007). However all of these models have lacked some parameters of the mill to be measured in an on-line manner. Mill models have also been developed for the purpose of monitoring key parameters and cross checking them against current operating conditions. Focus on the prediction and monitoring of coal moisture content is evident in the paper of Odgaard and Mataji (2007). In this paper the benefits are justified by the argument that it is better to have an estimate from current installed sensors, than to invest in new equipment to directly measure the moisture content. Models run on this basis are in fact assuming that the coal flow measurement reported by the feeder is an accurate input to the model. While this may be the case for power stations using gravimetric type feeders, the same cannot be said for power stations using volumetric type feeders, such as those studied herein.

\subsection{The energy balance model}

The change in internal energy of the system $\left(E_{s y s}\right)$ is equal to the difference in energy in and out, plus the energy generated internally (Fig. 4).

$$
\Delta E_{\text {sys }}=E_{\text {in }}-E_{\text {out }}+E_{\text {gen }}
$$




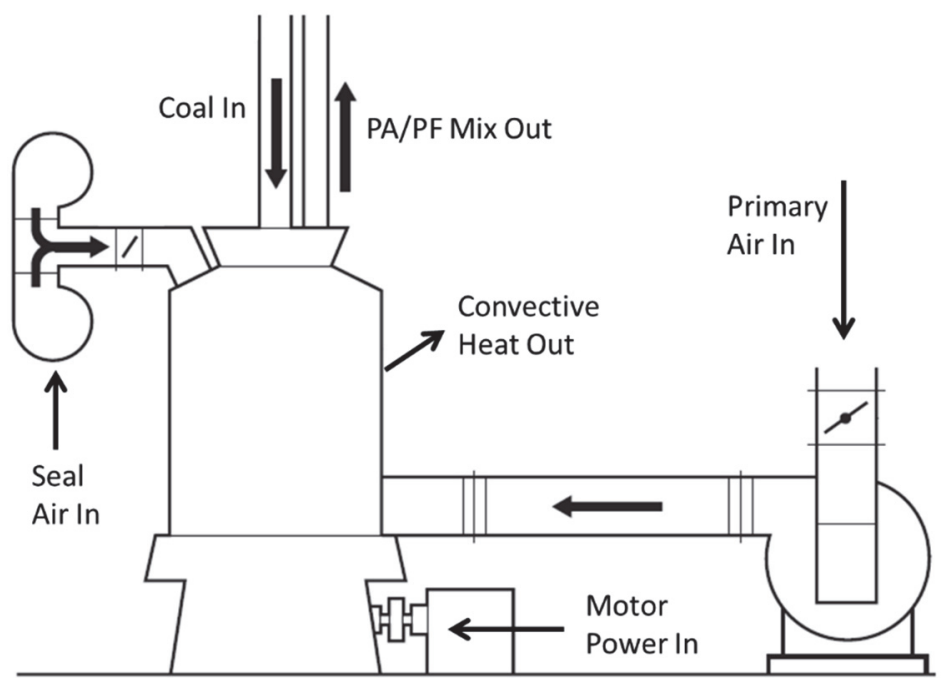

Fig. 4. Mill energy balance

Expressing this function as a rate we have:

$$
\frac{d E_{s y s}}{d t}=\dot{E}_{i n}-\dot{E}_{\text {out }}+\dot{E}_{g e n}
$$

For a steady state system the change in internal energy is zero. The mill is also considered to have no energy generation within the system. Therefore:

$$
\dot{E}_{\text {out }}=\dot{E}_{\text {in }}
$$

$\dot{E}_{i n}=($ Primary air in $)+($ Seal air in $)+($ Coal energy in $)+($ Motor power in $)$

$$
\begin{gathered}
\dot{E}_{\text {in }}=\left[\left(1-f_{P A}\right) \dot{m}_{P A} h_{P A_{\text {in }}}+\left(f_{P A}\right) \dot{m}_{P A} h_{P A_{H 2 O \text { in }}}\right]+\left[\left(1-f_{S A}\right) \dot{m}_{S A} h_{S A_{\text {in }}}+\left(f_{S A}\right) \dot{m}_{S A} h_{S A_{H 2 O \text { in }}}\right]+ \\
{\left[\left(1-f_{C}\right) \dot{m}_{C} h_{C_{\text {in }}}+\left(f_{C}\right) \dot{m}_{C} h_{C_{H 2 O \text { in }}}\right]+\left[M_{\text {Power }_{\text {in }}}\right]}
\end{gathered}
$$

where $f$ denotes the fraction of moisture contained in air or coal.

$\dot{E}_{\text {out }}=($ Primary air out $)+($ Seal air out $)+($ Coal energy out $)+\left(\right.$ Latent heat of vaporisation for $\mathrm{H}_{2} \mathrm{O}$ in coal) + (Convective heat loss)

$$
\begin{gathered}
\dot{E}_{\text {out }}=\left[\left(1-f_{P A}\right) \dot{m}_{P A} h_{P A_{\text {out }}}+\left(f_{P A}\right) \dot{m}_{P A} h_{P A_{H 2 O \text { out }}}\right]+\left[\left(1-f_{S A}\right) \dot{m}_{S A} h_{S A_{\text {out }}}+\left(f_{S A}\right) \dot{m}_{S A} h_{S A_{H 2 O \text { out }}}\right]+ \\
{\left[\left(1-f_{C}\right) \dot{m}_{C} h_{C_{\text {out }}}+\left(f_{C}\right) \dot{m}_{C} h_{C_{H 2 O \text { out }}}\right]+\left[\left(f_{C}\right) \dot{m}_{C} h_{V A P_{H 20} \text { o dog }}\right]+\left[q_{\text {out }}\right]}
\end{gathered}
$$

Rearranging to solve for the coal mass flow:

$$
\begin{gathered}
\dot{m}_{c}=\frac{\left(1-f_{P A}\right) \dot{m}_{P A}\left(h_{P A_{\text {in }}}-h_{P A_{\text {out }}}\right)+\left(f_{P A}\right) \dot{m}_{P A_{H 2 O}}\left(h_{P A_{H 2 O \text { in }}}-h_{P A_{H 2 O \text { out }}}\right)}{\left(1-f_{C}\right)\left(h_{C_{\text {out }}}-h_{C_{\text {in }}}\right)+\left(f_{C}\right)\left(h_{C_{H 2 O \text { out }}}-h_{C_{H 2 O \text { in }}}\right)+\left(f_{C}\right) h_{V A P_{H 2000 \mathrm{deg}}}}+ \\
\frac{\left(1-f_{S A}\right) \dot{m}_{S A}\left(h_{S A_{\text {in }}}-h_{S A_{\text {out }}}\right)+\left(f_{S A}\right) \dot{m}_{S A_{H 2 O}}\left(h_{S A_{H 2 O \text { in }}}-h_{S A_{H 2 O \text { out }}}\right)+M_{P \text { ower in }}-q_{\text {out }}}{\left(1-f_{C}\right)\left(h_{C_{\text {out }}}-h_{C_{\text {in }}}\right)+\left(f_{C}\right)\left(h_{C_{H 2 O \text { out }}}-h_{C_{H 2 O \text { in }}}\right)+\left(f_{C}\right) h_{V A P_{H 2090 \mathrm{deg}}}}
\end{gathered}
$$

The total mill differential pressure fluctuates at around $4 \mathrm{kPa}$. The bulk of the pressure drop occurs across the throat and across the classifier while the bulk of the enthalpy change occurs in the mill body 
between these two elements. It is therefore assumed that the pressure remains constant for the region of heat transfer from the hot primary air to the coal and seal air. In order to simplify the model it is assumed that the value of $C_{p}$ remains constant through this process. The following relationships then apply:

$$
\text { Enthalpy change of coal }=C_{P C O A L}\left(T_{\text {out }}-T_{\text {in }}\right)
$$

$C_{p C O A L}=1.26 \mathrm{~kJ} /(\mathrm{kg} \cdot \mathrm{K})$ (Sonntag et al., 1998)

Enthalpy change of air $=C_{p A I R}\left(T_{\text {in }}-T_{\text {out }}\right)$

$C_{p \mathrm{AIR}}=1.008 \mathrm{~kJ} /(\mathrm{kg} \cdot \mathrm{K})$ at $90^{\circ} \mathrm{C}$ (Incropera et al., 2007)

$$
\text { Enthalpy change of water }=C_{p}\left(T_{\text {in }}-T_{\text {out }}\right)
$$

$C_{p \mathrm{H} 2 \mathrm{O}}=1.993 \mathrm{~kJ} /(\mathrm{kg} \cdot \mathrm{K})$ at $90{ }^{\circ} \mathrm{C}($ Incropera et al., 2007)

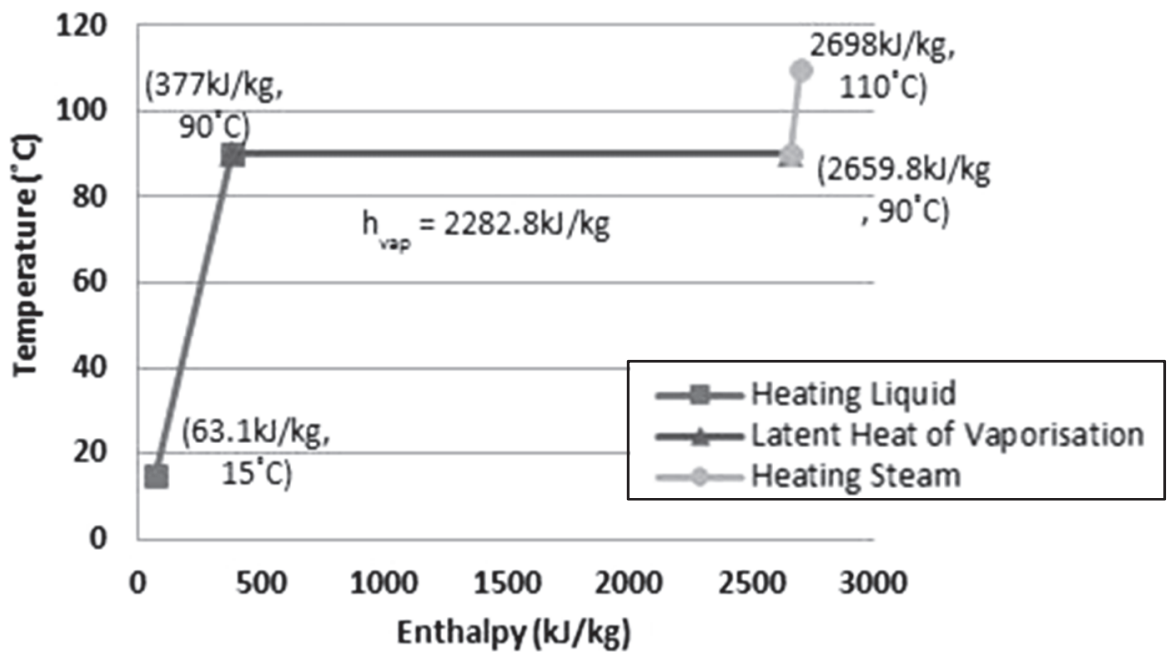

Fig. 5. Heating of moisture in coal

The heating and vaporisation of the moisture in coal is handled as per Fig. 5 showing temperature vs. enthalpy. In the liquid heating region the enthalpy is raised from $63.1 \mathrm{~kJ} / \mathrm{kg}$ to $377 \mathrm{~kJ} / \mathrm{kg}$ until it reaches the saturation temperature.

The heat of vaporisation of water at $90{ }^{\circ} \mathrm{C}$ raises the enthalpy by a further $2282.81 \mathrm{~kJ} / \mathrm{kg}$. No further heating of the vapour phase is assumed to happen as the mill outlet conditions are just below the vaporisation temperature of $95.1{ }^{\circ} \mathrm{C}$ (at $85 \mathrm{kPa}$ ).

Fixed inputs to the model include the raw coal temperature, seal air mass flow, primary air moisture, seal air moisture and convective heat loss. These are parameters that are not measured on-line, but may be recalculated using updated test data such as mill surface temperatures or updated weather data such as seasonal changes in temperature and relative humidity. The convective heat loss does contain some level of uncertainty as it is calculated using the approximate mill surface area and measurements of temperatures and air flows around the mill body. However, this parameter has a small effect on the final mass flow calculated. This can be seen in Fig. 8.

\subsection{Energy balance results}

The verification test parameters were derived from the Decentralised Control System (DCS) of five running mills, of an operational power station. The verification measurements and DCS values were 
taken after a feeder drop test and calibration was performed in order to be able to compare an accurate mass flow rate of the feeder to the calculated value of the MEB.

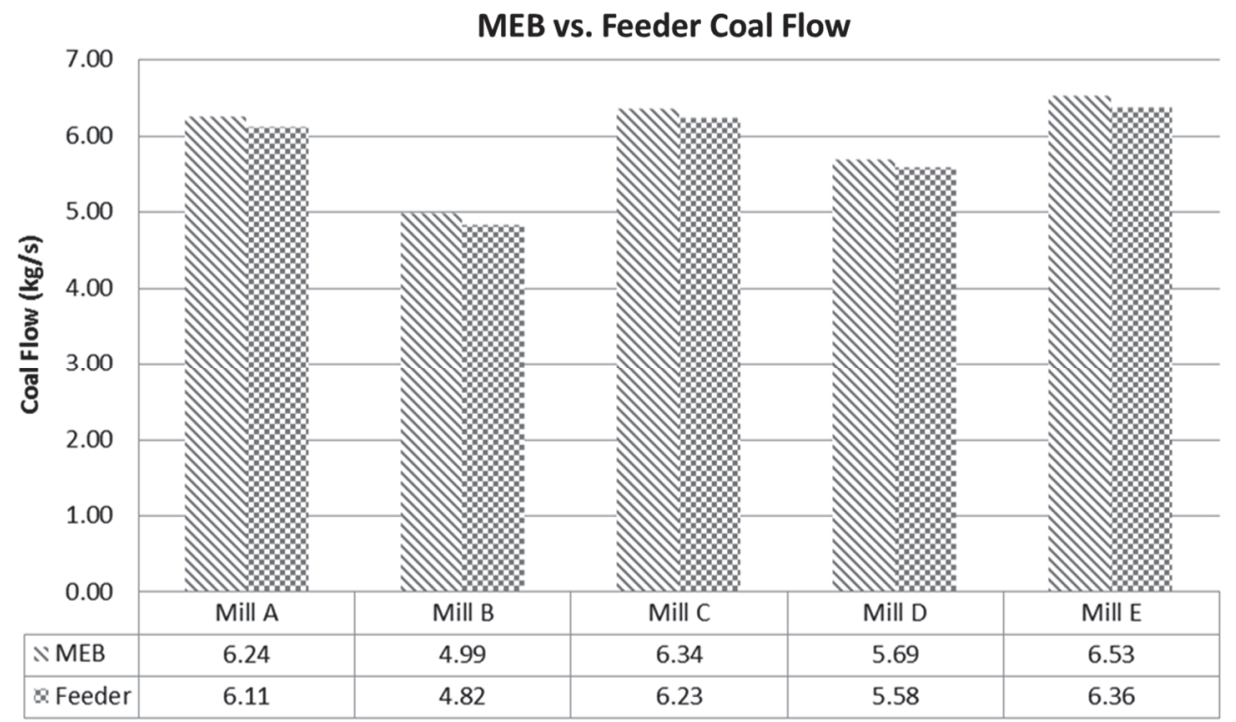

Fig. 6. MEB vs. feeder coal flow

Figure 6 shows that the MEB prediction compares well to the calibrated feeder result. Although the MEB tends to consistently predict a slightly higher coal flow rate than the calibrated feeder reports, the difference remains within the accuracy range of the applied MEB. The average difference between the MEB prediction and the feeder measurement is $2.33 \%$ overall. This over-prediction could be attributed to inaccurate $C_{p}$ values under fluctuating conditions, any combination of measurement errors or even transients in operation. The measurement uncertainty of the volumetric based, screw type coal feeder is estimated to be in the region of $10 \%$ to $15 \%$. This is based on past experience by comparing the coal flow to boiler mass and energy balances as well as test data from ball injection tests performed on these feeders.

Propagating the measurement uncertainties of each of the input parameters in Fig. 7 below, results in an overall coal mass flow calculation uncertainty of 5.13\%. In Fig. 7 the calculation error as a result of each individual measurement uncertainty is shown.

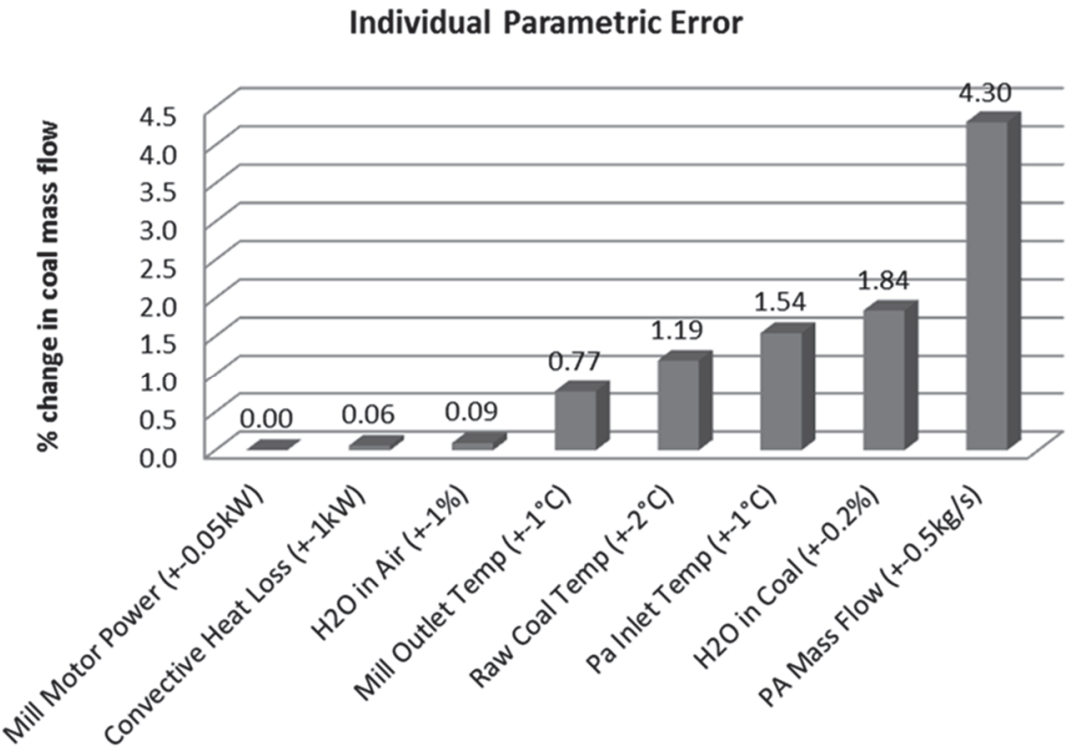

Fig. 7. Individual parametric error 
From this it can be seen that the PA mass flow propagates the greatest individual error in coal mass flow of $4.3 \%$ as a result of the measurement uncertainty. This is followed by the coal moisture, PA inlet temperature and raw coal temperature in the region of $1 \%$ to $2 \%$.

A calculation sensitivity analysis evaluating the effect on the predicted coal flow, by varying each input parameter by $\pm 10 \%$ to the norm, is shown in Fig. 8 . The primary air temperature and mass flow as well as the mill outlet temperature have the largest effect on the calculation.

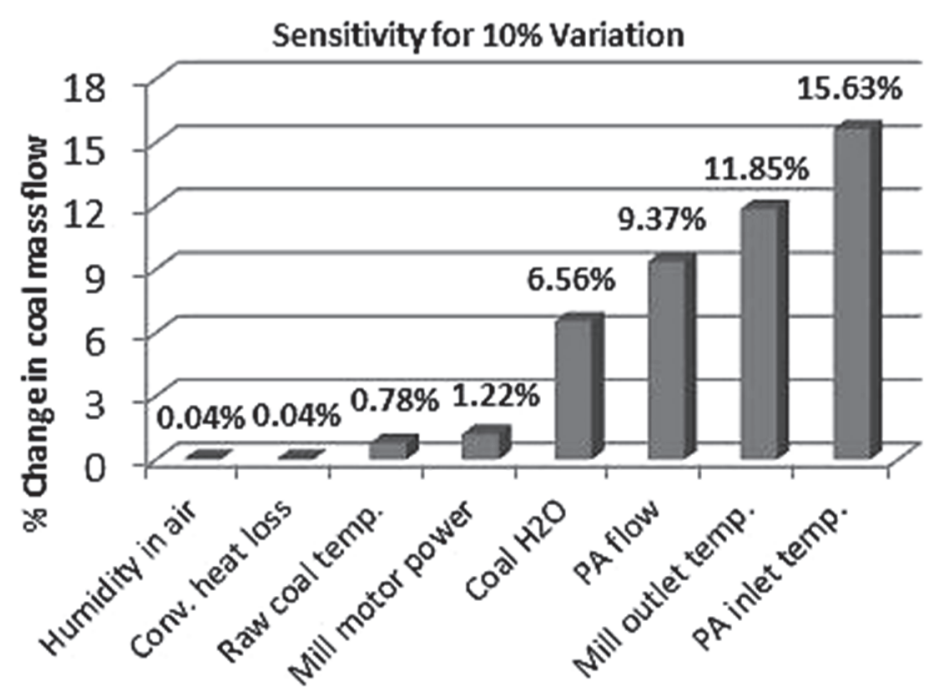

Fig. 8. Bar graph of the average sensitivity of input parameters

These values are however well known as they are fairly accurately measured in an on-line manner. Of concern is the sensitivity of variations in the coal moisture on the coal flow calculation.

While the coal moisture may be accurately measured in a lab environment, the coal sample is taken manually and periodically once a day. A $10 \%$ change in coal moisture results in a $6.56 \%$ error on the coal flow prediction. A coal moisture variation of $10 \%$ of its last measured value within a day is a likely possibility in a power station environment. Therefore it is advised to increase the reliability of the coal flow prediction model by measuring the coal moisture using an on line coal moisture analyser and pass this value into the MEB model in a real-time manner.

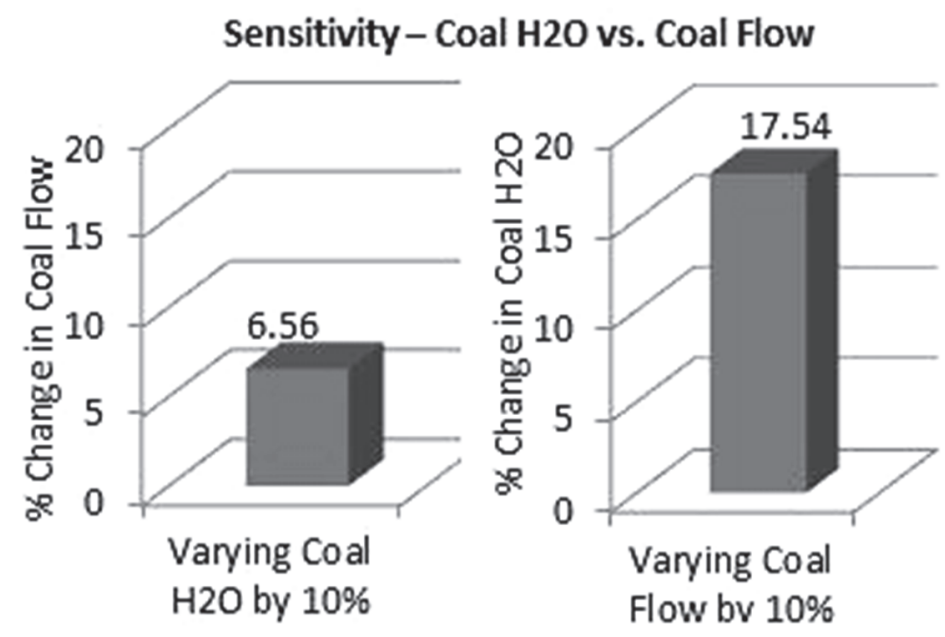

Fig. 9. Sensitivity of coal moisture and coal flow 
Investigating the possibility of measuring the coal mass flow by means of a gravimetric coal feeder, and using a measured coal flow value to calculate the coal moisture using the energy balance, leads to the asymmetry of sensitivity shown in Fig. 9.

From Fig. 9 above it can be seen that a 10\% change in coal mass flow results in a $17.54 \%$ change in coal moisture. This makes it more than twice as sensitive as changes in the coal moisture. The model is therefore more accurate in determining the coal mass flow, using coal moisture as an input, than it is at calculating the coal moisture using the coal mass flow as an input. This is in line with Odgaard and Mataji (2007) who described the high inaccuracy of moisture prediction as a "noisy measurement".

\subsection{Discussion}

The mill energy balance tool successfully predicts the coal mass flow within $2.33 \%$ of a calibrated feeder. This is within the bands of both the screw feeder uncertainty as well as the propagated MEB calculation error. However, it does have some shortcomings in the context of an on-line mass flow monitoring tool. All input parameters are measured on-line and information is passed directly to the calculation, apart from the coal moisture. The coal moisture is determined by taking a sample from the coal feeder and lab drying it to determine the change in mass and thus the moisture content. This value is then fixed in the calculation until the next daily coal moisture results become available. The implementation of an on-line coal moisture analyser would provide the necessary input data to reduce the effect of this error in the calculation. The alternative solution is to modify the MEB to calculate the coal moisture using a means of coal mass flow measurement (such as a gravimetric feeder) as an input to the model. The sensitivity analysis showed that the model is more sensitive to to changes in the coal mass flow, than it is to changes in the coal moisture, as an input parameter (Fig. 9). This suggests that in order to take advantage of the sensitivity of the calculation to improve the accuracy of the result, it is beneficial to measure accurately the coal moisture as an input to the model, and calculate the coal mass flow as an output.

\section{PARTICLE SIZE ANALYSER TESTING}

\subsection{Particle size analyser outline}

The particle size analyser is made up of a system of components. The probe itself consists of a long cylindrical shaft with a groove cut perpendicular to its length and near the tip. The laser eye fires longitudinally and across this groove to measure the size of pulverised fuel particles as they pass through the groove. This is shown in Fig. 10.

The probe also feeds purge air to the laser eye in order to maintain the cleanliness of the lens and the optical sensor on the other side. This purge air is fed from both the laser transmitter and optical sensor end and is done so in the direction of the flow of PF through the groove. The pressure and mass flow rate of the purge air is controlled via a purge controller which can perform a continuous or periodic purge.

As the shaft is inserted into the PF pipe to take measurements of the particle size distribution, there are five measurement parameters that can be controlled by the operator. The probe can be rotated in the test port to change the angle of the measurement groove in comparison to the PF flow inside the pipe. The purge air can be controlled in terms of purge air pressure, flow rate and purging time. And finally the physical depth of measurement inside the PF pipe can be changed. 


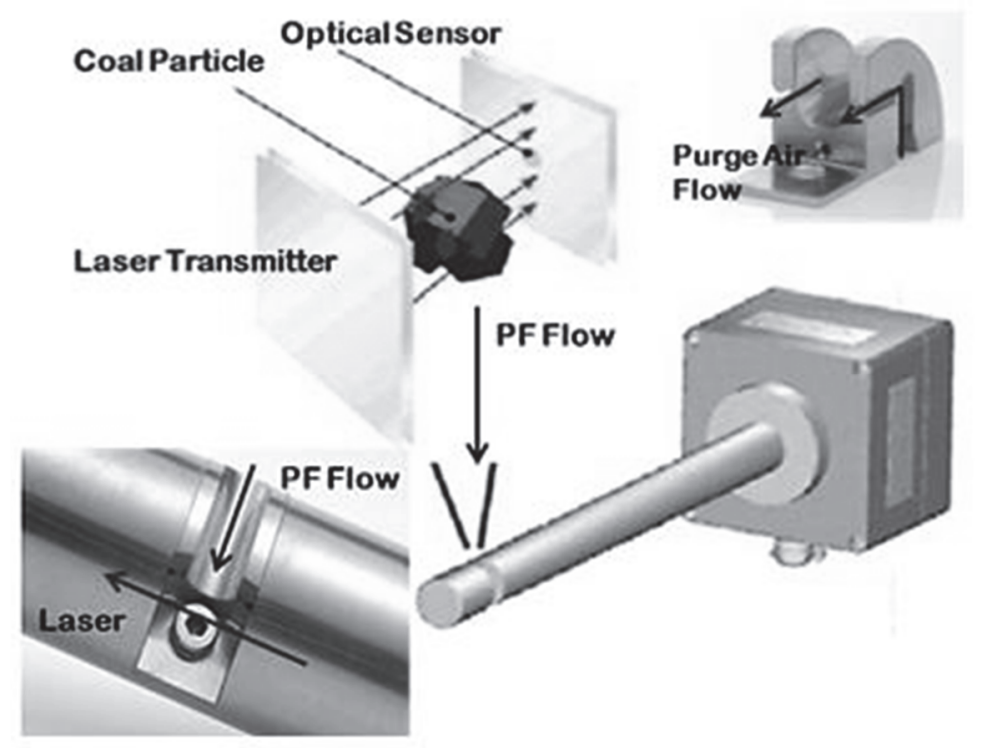

Fig. 10. PSA Principle of Operation (Parsum, 2011)

These five measurement parameters have been shown to have an effect on the reported or perceived particle fineness results. The relationships that exist between the measurement parameters and the results have been defined below in order to improve the reliability and accuracy of results.

\subsection{Literature review}

Particle characterisation technology has evolved vastly over the last four decades. A summary of the evolution of particle size analysis technologies was made by Dodds et al. (2004). It was noted that the means of characterising a particle has not differed from the basic principles of particle size and particle size distribution. New technologies employed have however, transformed the industry away from laboratory analysis. These involve off-line measurements made using direct methods (counters, microscopy) or field classification methods (sedimentation, sieving). Instead, secondary methods of measurement and analysis (laser diffraction, spatial filtering, ultra-sound attenuation) have taken precedence thereby moving the particle size analysis from the laboratory to the process plant using online technologies and modern computing for real time analysis.

The iso-kinetic sampling and sieving process has been established as the standard method of determining the particle size distribution of PF in the power generation industry. The term "iso-kinetic" implies that the PF is extracted at the same velocity that it would have otherwise been travelling through the PF pipe had the probe not been present.

This is said to be achieved by adjusting the vacuum generated inside the probe used for the extraction of PF. The static pressure inside the PF pipe (P2) is monitored, as is the static pressure inside the extraction probe (P1). For as long as these two pressures (P1 and P2 in Fig. 11) are maintained as equal, the sampling is considered to be iso-kinetic.

The PF is separated from the air by two cyclone separators in series and stored in the glass collection jars. The sample is then taken to the lab to be dried, weighed and sieved before a particle size distribution is available for analysis.

This is a lengthy and labour intensive process that is performed bi-annually per mill, or upon suspicion of a problem. Such results are impossible to use in a performance or condition monitoring role as the measurements are not frequent enough. The results are also influenced by the possibility of human error during the testing process. 


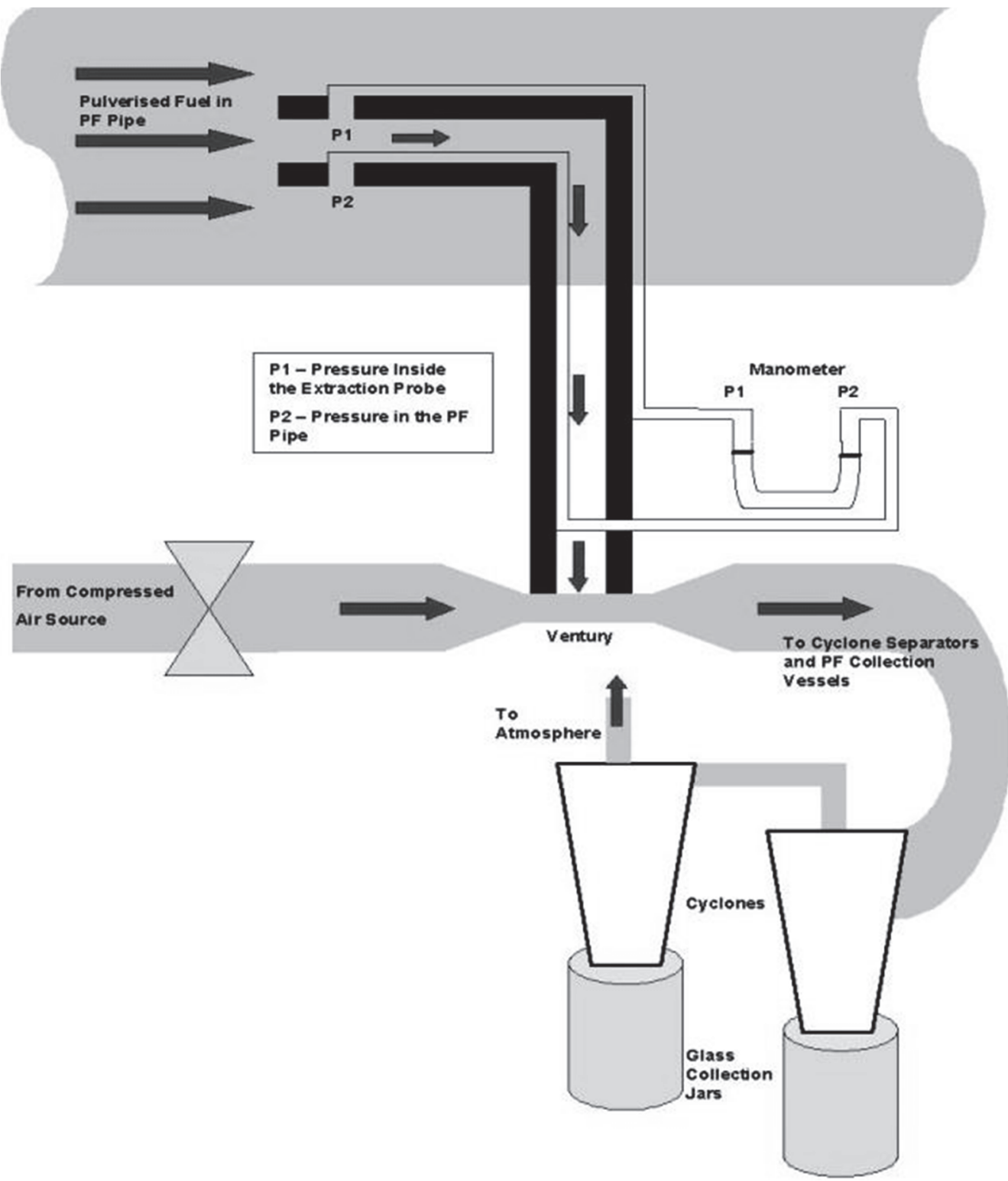

Fig. 11. Iso-kinetic sampler principle of extraction

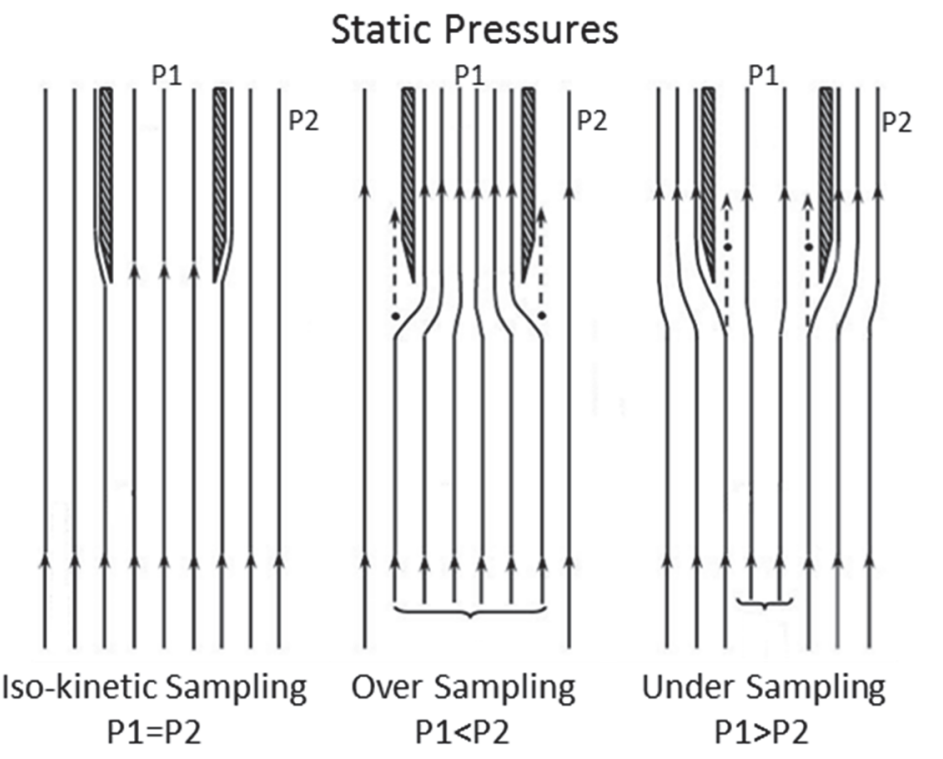

Fig. 12. Under-sampling and Over-sampling (Jerez et. al. 2006) 
The pressure in the PF pipe (P2) is constantly fluctuating and therefore one has to constantly adjust the pressure inside the probe (P1) accordingly in order for them to match. If there is a pressure differential between these two values for any discernible period of time then one begins to under-sample or oversample depending on which pressure is higher as illustrated in Fig. 12. Under-sampling produces results that are too coarse, while over-sampling produces results that are too fine as compared to a correct sample.

Furthermore, the iso-kinetic sampler used has a $90^{\circ}$ fixed extraction probe and a single point of entry in the PF pipe. In order for the probe tip to extract PF from every point of the pipe cross section illustrated in Fig. 22, the probe must be angled towards the side walls for points that lie off its axis of insertion. However, with the probe now at an angle to the flow, it is incorrect for the pressures to be equalized in order to extract a sample iso-kinetically. Sampling along three axes $60^{\circ}$ apart or using a rotating head sampler will improve the consistency of results but ultimately they remain prone to considerable error. All of these points considered, the iso-kinetic sampling and sieving process has still been accepted world-wide as the standard method of particle size distribution measurement in power generation. The most significant change in particle size analysis technology has been attributed to the shift of measurement techniques towards methods that are based on the interaction of particles with light. Petrak (2002) developed a method of using fibre-optic spatial filtering velocimetry (SFV), modified by fibre-optical spot scanning (FSS), in order to determine the particle size. Spatial filtering velocimetry is a method of determining the velocity of an object by observing it through a spatial filter in front of a receiver. The details of which have been explained in the paper by Aizu and Asakura (1987). The modified spatial filtering technique as described by Petrak (2002) employs fibre-optical spot scanning (FSS) as an addition to the SFV. Fibre-optical spot scanning observes the projected shadow of a particle as it moves across an optical fibre. As the shadow image is passed across the single fibre, an impulse is generated as illustrated in Fig. 13. The width of the shadow (or chord length) is dependent on the particle size, the particle velocity, and the random spatial location of the particle and fibre (Petrak, 2002). In this way the chord length of the projected surface of an individual particle is measured.

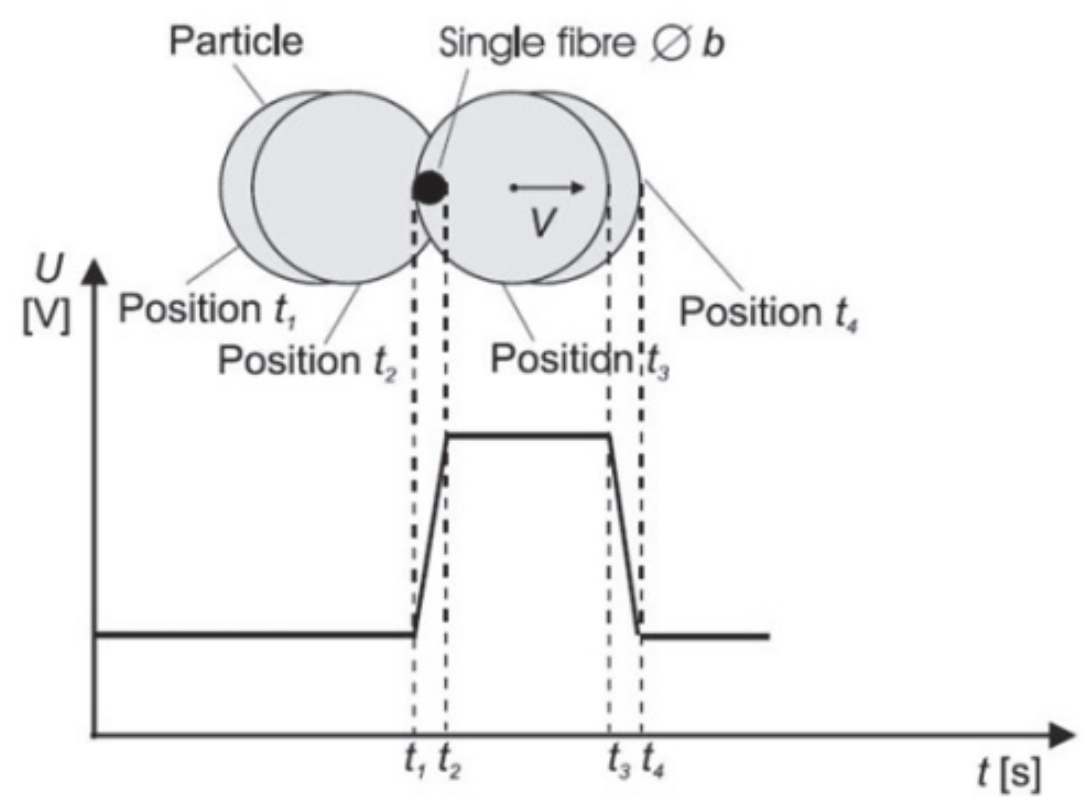

Fig. 13. Impulse Generated by Fibre-optic Spot Scanning (Petrak, 2002) 


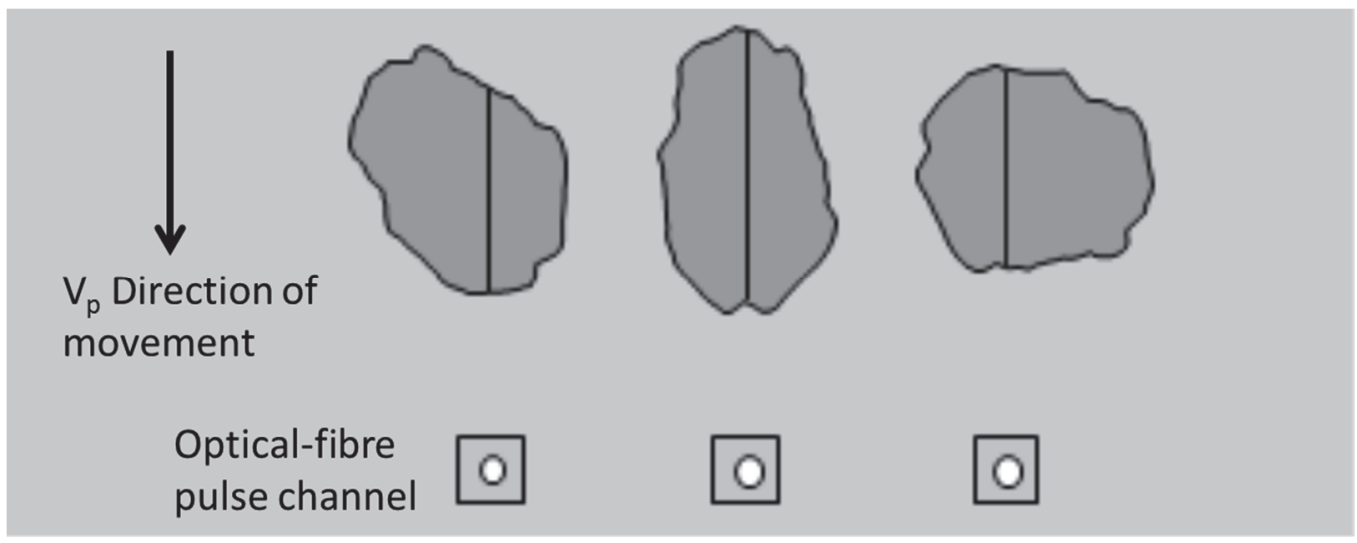

Fig. 14. Chord Lengths of Projected Face

Furthermore, it has been shown that Bayes' theorem may be used to determine the particle size analysis using these chord length measurements (Langston et al., 2001). Fig. 14 shows that the chord length is the link between two points on the perimeter of the measured particle's projection face. The chord length is used to describe the particle size as a single statistical value, and is largely dependent on the orientation as well as the trajectory of the particle. The statistical evaluation of a specified quantity of individual particles is required in order to achieve a representative particle-size analysis.

Figure 15 illustrates the schematic arrangement of the measurement components as a coal particle passes through it. The particle size analyser (PSA) tested herein utilises this method of spatial filtering velocimetry and fibre-optic spot scanning to determine a particle size distribution of pulverised fuel from the mill.

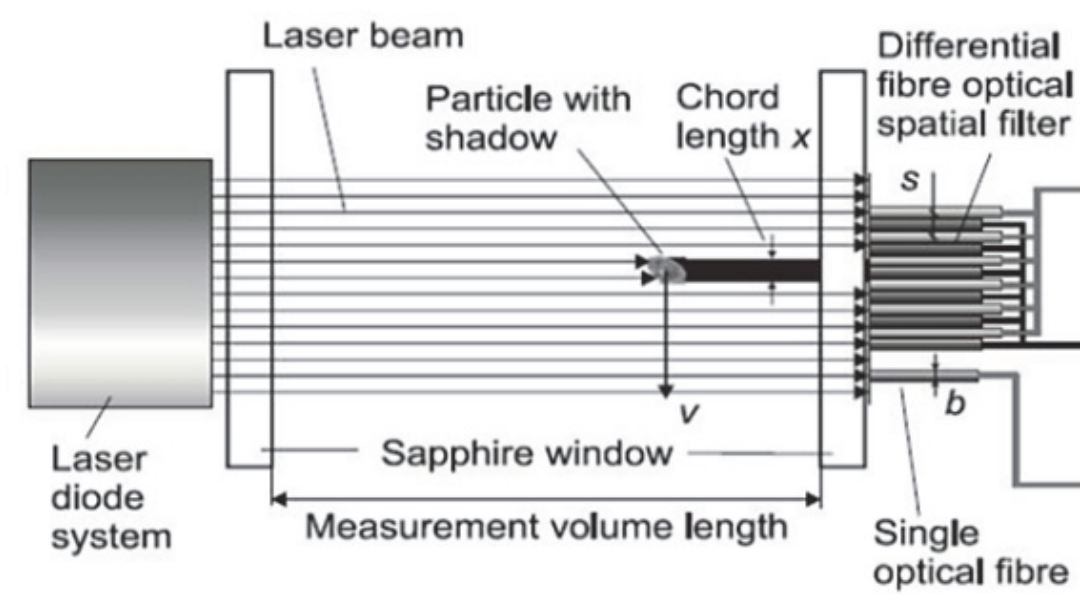

Fig. 15. Chord length measurement using FSS and SFV (Petrak, 2002)

\subsection{Particle size analyser testing}

Initial tests were performed on the Power Station as per the manufacture's test procedure. This was performed to compare between the results of simultaneous PSA and iso-kinetic sampling and sieving. The mills were operated in manual mode for the period of testing to prevent mill load changes due to the control system responses to the boiler energy requirements. A single pipe of mills 2B and 2D (Fig. 16) was first tested using iso kinetic sampling and then tested using the particle size analyser for a period of 15 minutes. 


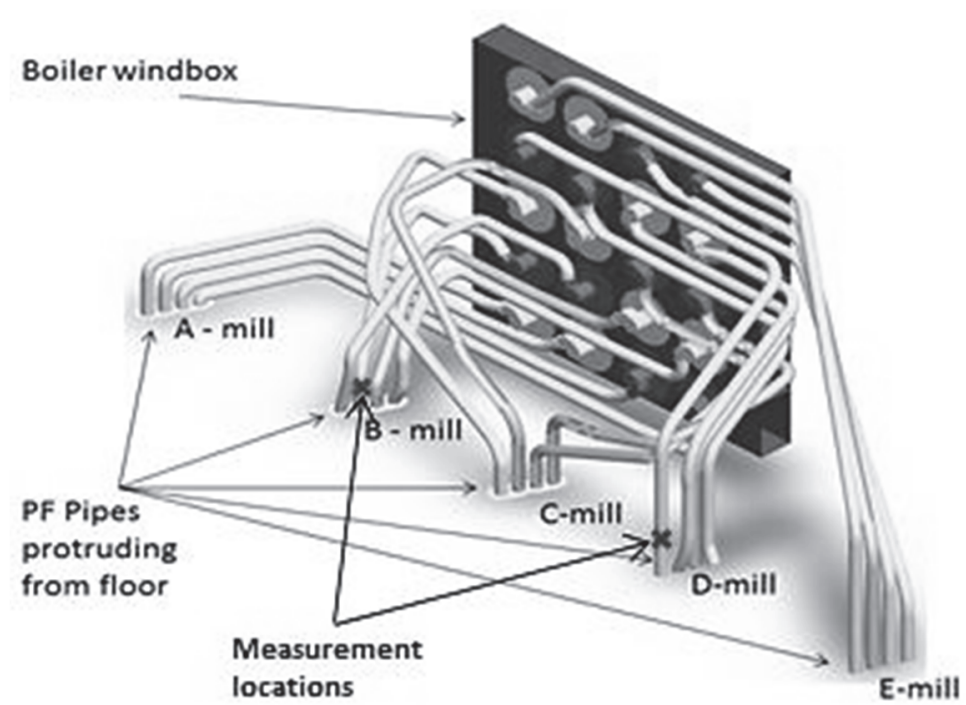

Fig. 16. Measurement locations above burner floor

Each pair of tests was performed 4 times to show repeatability. The original PSA test settings were maintained initially and adjusted in later tests in order to test various sensitivities. Initial test settings were, a measurement point at $50 \mathrm{~mm}$ into the PF pipe, purge air settings of 3 bar pressure, $10 \mathrm{~L} / \mathrm{m}$ flow rate and 4 seconds of purging time. In the Investigation Findings below, detailed analysis was performed on mill 2B by varying these parameters as well as the probe orientation individually in order to determine the effect that they have on the reported particle fineness results. The PSA has shown consistency and repeatability during these initial tests. The largest differences in repeated PSA tests were noticeable at $75 \mu \mathrm{m}$ and $106 \mu \mathrm{m}$ (2.24 and 2.17 percentage points, respectively). This can be seen in Table 1.

Table 1. PSA repeatability test results

\begin{tabular}{|c|c|c|c|c|c|c|}
\hline & Test 1 & Test 2 & Test 3 & Test 4 & Max \% diff & $\begin{array}{c}\% \text { of } \\
\text { Window }\end{array}$ \\
\hline$\%<300 \mu \mathrm{m}$ & $99.56 \%$ & $99.61 \%$ & $99.43 \%$ & $99.62 \%$ & $0.19 \%$ & $23.75 \%$ \\
\hline$\%<150 \mu \mathrm{m}$ & $93.41 \%$ & $93.51 \%$ & $93.24 \%$ & $93.91 \%$ & $0.67 \%$ & $12.18 \%$ \\
\hline$\%<106 \mu \mathrm{m}$ & $82.34 \%$ & $84.32 \%$ & $83.12 \%$ & $84.50 \%$ & $2.17 \%$ & $20.61 \%$ \\
\hline$\%<75 \mu \mathrm{m}$ & $65.46 \%$ & $67.69 \%$ & $66.59 \%$ & $66.43 \%$ & $2.24 \%$ & $22.35 \%$ \\
\hline
\end{tabular}

The optimal fineness window is defined as the optimal particle fineness for complete combustion of the coal particles within the furnace height whilst not being so fine as to cause propensity for slag formation in the furnace region. This is outlined in Table 2 and is represented by the area between the two straight lines on the Rosin Rammler plot in Fig 17.

Table 2. Optimal fineness window

\begin{tabular}{|c|c|c|c|}
\hline $\begin{array}{c}\text { Optimal } \\
\text { Window }\end{array}$ & Minimum & Ideal & Maximum \\
\hline$\%<300 \mu \mathrm{m}$ & $99.00 \%$ & $99.40 \%$ & $99.80 \%$ \\
\hline$\%<150 \mu \mathrm{m}$ & $89.00 \%$ & $91.75 \%$ & $94.50 \%$ \\
\hline$\%<106 \mu \mathrm{m}$ & $76.00 \%$ & $81.25 \%$ & $86.50 \%$ \\
\hline$\%<75 \mu \mathrm{m}$ & $65.00 \%$ & $70.00 \%$ & $75.00 \%$ \\
\hline
\end{tabular}




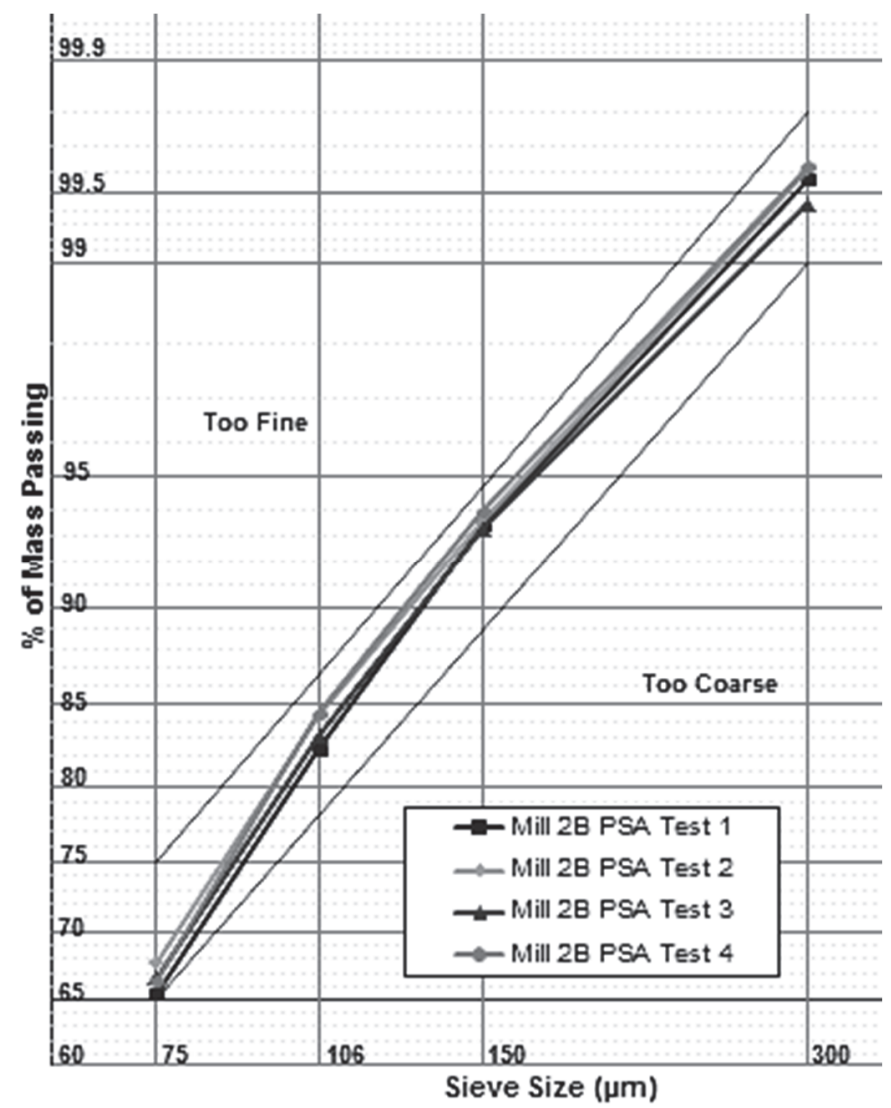

Fig. 17. PSA repeatability test results

Although the percentage difference in the optimal fineness window at the $300 \mu \mathrm{m}$ particle size level is the highest, overall the difference is $0.19 \%$ of the mass of particles less that $300 \mu \mathrm{m}$. This is much less than the instrument's measurement uncertainty.

Comparing the PSA results to those of the iso-kinetic sampling, it was found that the PSA was consistent in trend to that of the iso-kinetic sampling results. However the absolute value of reported results differed for the mills of the same unit and load conditions. On mill 2B the difference was as high as 4.98 percentage points at $106 \mu \mathrm{m}$. To put that in perspective it equates to $47.7 \%$ of the optimal fineness window. The PSA results of mill $2 \mathrm{~B}$ at the $300 \mu \mathrm{m}$ particle size deviates from the iso-kinetic sampling results by $123 \%$, which is larger than the window itself. Focussing on mill 2B in Table 3 the PSA results indicate that the mill is grinding optimally whereas the iso-kinetic results indicate the mill is grinding too coarse and the mill would need adjustment.

Table 3. Iso-kinetic sampling vs. PSA results

\begin{tabular}{|c|c|c|c|c|c|c|}
\hline & 2B Iso & 2B PSA & 2D Iso & 2D PSA & Max \% diff & $\begin{array}{c}\% \text { of } \\
\text { Window }\end{array}$ \\
\hline$\%<300 \mu \mathrm{m}$ & $98.63 \%$ & $99.61 \%$ & $99.73 \%$ & $99.01 \%$ & 2B @ $0.98 \%$ & $123.12 \%$ \\
\hline$\%<150 \mu \mathrm{m}$ & $90.03 \%$ & $93.51 \%$ & $95.74 \%$ & $92.10 \%$ & 2D @ 3.64\% & $66.18 \%$ \\
\hline$\%<106 \mu \mathrm{m}$ & $79.34 \%$ & $84.32 \%$ & $89.00 \%$ & $84.52 \%$ & 2B @ $4.98 \%$ & $47.47 \%$ \\
\hline$\%<75 \mu \mathrm{m}$ & $64.46 \%$ & $67.69 \%$ & $76.59 \%$ & $71.89 \%$ & 2D @ 4.70\% & $46.95 \%$ \\
\hline
\end{tabular}

The opposite was found on mill 2D, where the PSA showed results that are coarse as compared to the iso-kinetic sample. The differences between iso-kinetic sampling and PSA results at the four sieve sizes are shown in Fig. 18. 


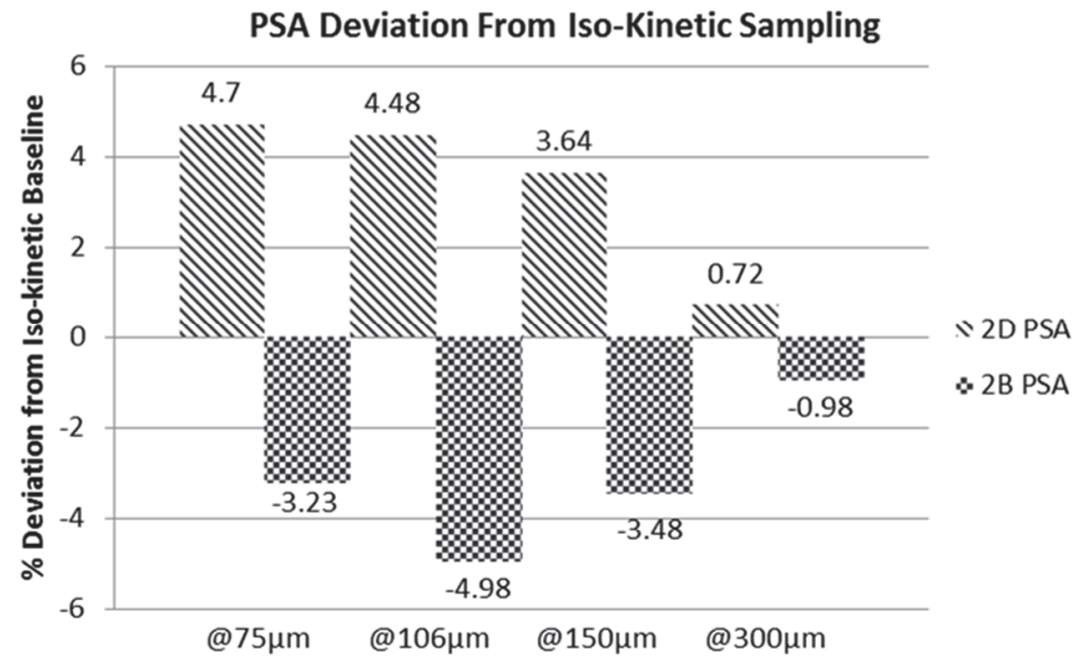

Fig. 18. PSA Deviation from iso-kinetic results

This type of instrument behaviour (good repeatability but poor absolute prediction) is indicative of high precision and low accuracy performance, as generally accepted by the Joint Committee for Guides in Metrology (JCGM, 2012).

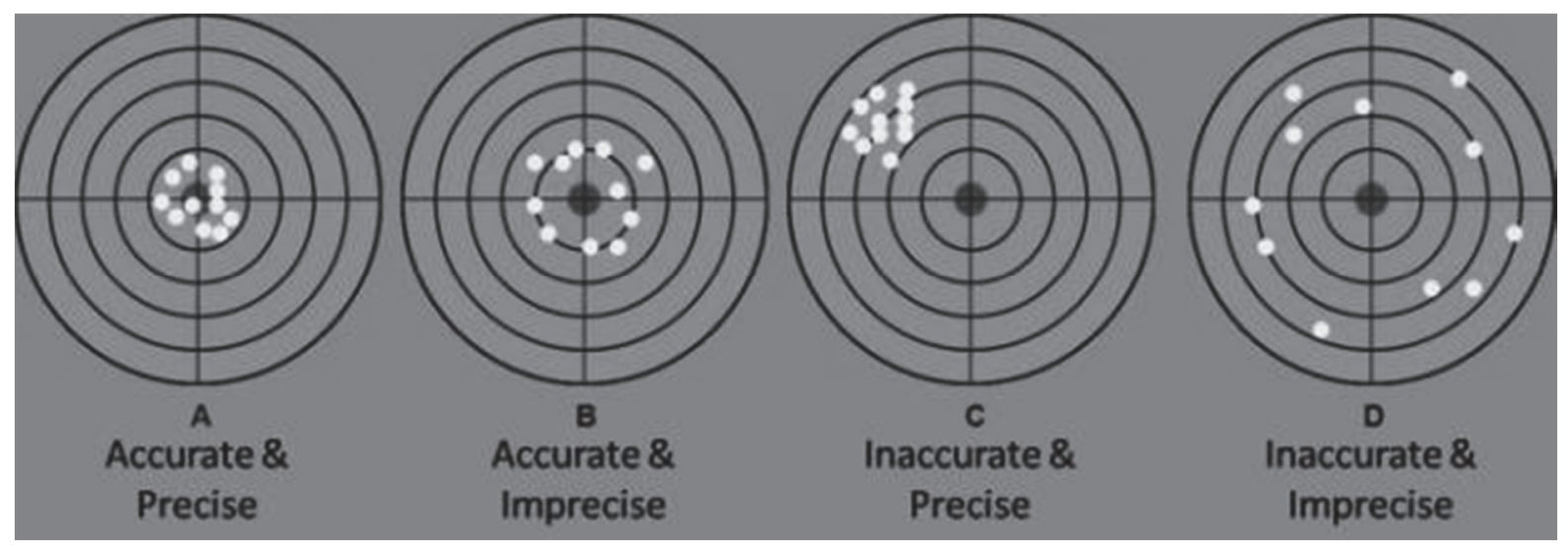

Fig. 19. Accuracy vs. precision

The behaviour indicated by $\mathrm{C}$ in Fig. 19, is under normal circumstances, attributed to an instrument that requires a calibration to be performed in order to improve the accuracy, and thus produce results that are both repeatable (precise) and correct (accurate). However in the case of the PSA, the probe does not require a measurement calibration as it measures directly the chord lengths of every particle that passes through the laser. This prompted an investigation to determine what other parameters are affecting the results of the PSA under power station conditions. The objectives were to understand how the test procedures and test parameters around the PSA could affect the reported results. Once this has been understood one may be able to commission the equipment for accurate repeatable results.

\subsection{Investigation findings}

\subsubsection{Probe angle effect}

The first thing to note is the effect that the orientation of the probe plays on the perceived results. This is due to the shape and orientation of the groove that the PF must pass through in order to pass the laser eye. 

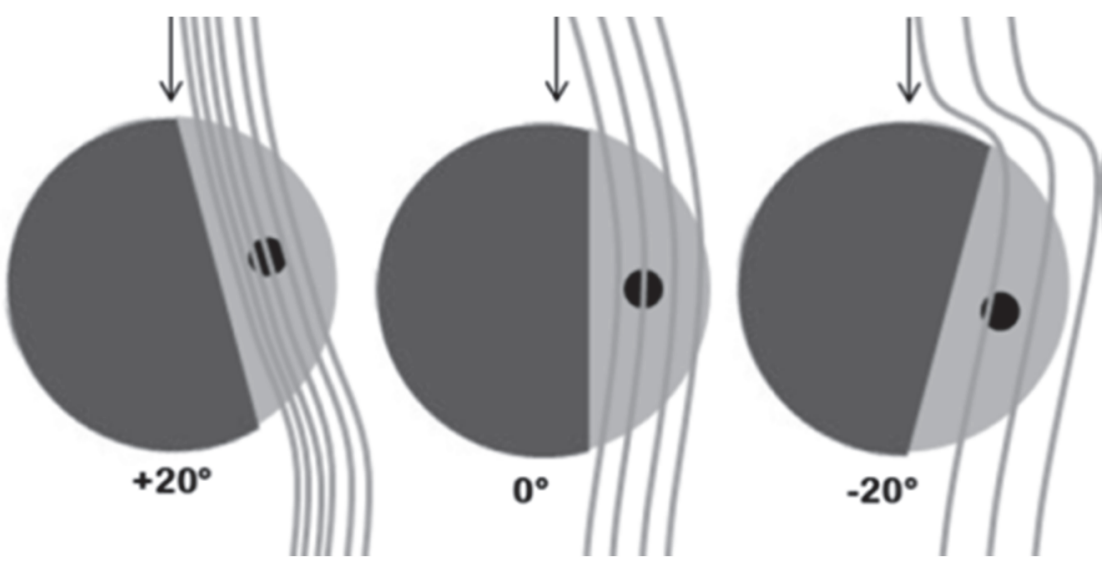

Fig. 20. Flow patterns for different PSA orientations

Figure 20 illustrates the flow pattern that the laser eye should see. However, when one considers the poly-dispersed two phase nature of the flow, questions may be raised as to the paths and deflections of the different sized particles either away or into the measurement path. The test conducted was aimed to study the effects of the probe orientation on the reported PF fineness.

Measurements of PF fineness were taken for orientations of $0^{\circ}, 10^{\circ}$ and $20^{\circ}$ in each direction (Table 4 and Fig. 20). The $0^{\circ}$ orientation represents the correct orientation with respect to a fully developed pipe flow. The effects of turbulence and upstream flow stratifications are not considered and thus it must be noted that the angle at which the particles approach the probe may differ.

The results at the various sieve sizes are consistent in their behaviour. From $0^{\circ}$ rotating counterclockwise to $+10^{\circ}$ the particle fineness sharply increases, and the results fail to show at $+20^{\circ}$ due to the PF building up to block the laser eye. At that stage the angle is too large to allow a flow of PF through its desired path.

When rotating the probe clockwise from $0^{\circ}$ to $-10^{\circ}$, the particle fineness sharply drops indicating that finer particles are being deflected away from the path of the laser eye, or more of the larger particles are allowed towards the eye. This is counter intuitive as it is expected that smaller particles would follow the fluid path more closely.

Rotating the probe further on, the results pass an inflection point and the particle fineness drastically increases once again. This indicates that at this higher angle, the coarser particles are more easily deflected away from the desired path and more fines are being measured. Either way, the effect of changing the angle of the probe as inserted into the PF pipe has an adverse and drastic effect on the reported results. Within $\pm 10^{\circ}$ the results appear finer when the laser eye is angled towards the flow and coarser when angled away from the flow.

Table 4. Percentage passing for different PSA orientations

\begin{tabular}{|c|c|c|c|c|c|}
\hline $\begin{array}{c}\text { @ } 3 \mathrm{bar}, 10 \mathrm{~L} / \mathrm{m}, \\
50 \mathrm{~mm}, 4 \mathrm{~s}\end{array}$ & $+20^{\circ}$ & $+10^{\circ}$ & $0^{\circ}$ & $-10^{\circ}$ & $-20^{\circ}$ \\
\hline$\%<300 \mu \mathrm{m}$ & $0 \%$ & $99.9 \%$ & $99.6 \%$ & $98.7 \%$ & $99.8 \%$ \\
\hline$\%<150 \mu \mathrm{m}$ & $0 \%$ & $97 \%$ & $94 \%$ & $86 \%$ & $93 \%$ \\
\hline$\%<106 \mu \mathrm{m}$ & $0 \%$ & $89 \%$ & $82 \%$ & $70 \%$ & $86 \%$ \\
\hline$\%<75 \mu \mathrm{m}$ & $0 \%$ & $72 \%$ & $62 \%$ & $51 \%$ & $71 \%$ \\
\hline
\end{tabular}




\subsubsection{Purge air pressure and mass flow effect}

The second area of investigation was based around the effect of the mass flow rate and pressure of the purge air supplied to the laser eye. It is hypothesised that the purge air may be instrumental in deflecting the fine or coarse particles away from the laser eye and measurement path (Hayden et al., 2003), as illustrated in Fig. 21.

Tests on mill 2B revealed the results shown in Table 5, which shows that the increased pressure displaces finer (lower momentum) particles from the natural path creating a bias towards the larger particles.

Table 5. Purge air pressure results

\begin{tabular}{|c|c|c|c|c|c|}
\hline $\begin{array}{c}@ 10 \mathrm{~L} / \mathrm{m}, \\
50 \mathrm{~mm}, 4 \mathrm{~s}\end{array}$ & 2 bar & 3 bar & 4 bar & Max \% diff & $\begin{array}{c}\% \text { of } \\
\text { Window }\end{array}$ \\
\hline$<300 \mu \mathrm{m}$ & $99.73 \%$ & $99.58 \%$ & $99.52 \%$ & $0.21 \%$ & $26.25 \%$ \\
\hline$<150 \mu \mathrm{m}$ & $96.08 \%$ & $95.93 \%$ & $95.16 \%$ & $0.92 \%$ & $16.72 \%$ \\
\hline$<106 \mu \mathrm{m}$ & $86.99 \%$ & $86.98 \%$ & $85.97 \%$ & $1.02 \%$ & $9.71 \%$ \\
\hline$<75 \mu \mathrm{m}$ & $67.46 \%$ & $67.49 \%$ & $66.65 \%$ & $0.84 \%$ & $8.40 \%$ \\
\hline
\end{tabular}

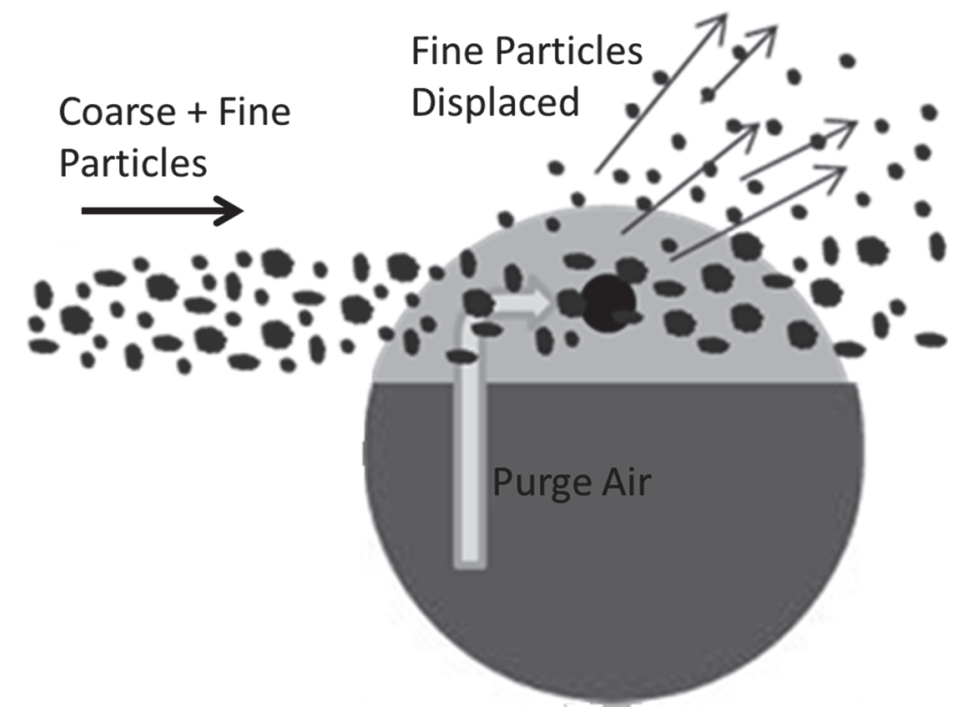

Fig. 21. Purge air affecting particle flow

An increase in mass flow of purge air, on the other hand, acts to produce a finer result as per Table 6 . As the purge air mass flow is increased, so do the reported results of PF fineness. The difference is as high as 1.92 percentage points at the $75 \mu \mathrm{m}$ particle size, while the $300 \mu \mathrm{m}$ particle size group can change by $51.25 \%$ of the optimal fineness window.

Table 6. Purge air mass flow results

\begin{tabular}{|c|c|c|c|c|}
\hline $\begin{array}{c}\text { @ } \begin{array}{c}3 \text { bar, } 50 \mathrm{~mm}, \\
4 \mathrm{~s}\end{array} \\
<300 \mu \mathrm{m}\end{array}$ & $5 \mathrm{~L} / \mathrm{m}$ & $10 \mathrm{~L} / \mathrm{m}$ & $\begin{array}{c}\text { Max } \\
\% \text { diff }\end{array}$ & $\%$ of Window \\
\hline$<150 \mu \mathrm{m}$ & $99.31 \%$ & $99.72 \%$ & $0.41 \%$ & $51.25 \%$ \\
\hline$<106 \mu \mathrm{m}$ & $85.31 \%$ & $95.38 \%$ & $1.07 \%$ & $19.45 \%$ \\
\hline$<75 \mu \mathrm{m}$ & $67.25 \%$ & $86.81 \%$ & $1.64 \%$ & $15.61 \%$ \\
\hline
\end{tabular}




\subsubsection{Purge air time effect}

The final purge air parameter to evaluate is the period of each purge. The purge settings allow for a burst of purge air to blow for either 2 or 4 seconds, with a 30 second interval between purges. Table 7 shows the effect of increasing the purge time, on the particle fineness.

Table 7. Purge air time results

\begin{tabular}{|c|c|c|c|c|}
\hline $\begin{array}{c}\text { @ } \begin{array}{c}3 \text { bar, } 10 \mathrm{~L} / \mathrm{m}, \\
50 \mathrm{~mm}\end{array} \\
<300 \mu \mathrm{m}\end{array}$ & $2 \mathrm{~s}$ & $4 \mathrm{~s}$ & Max \% diff & $\%$ of Window \\
\hline$<150 \mu \mathrm{m}$ & $99.72 \%$ & $99.51 \%$ & $0.21 \%$ & $26.25 \%$ \\
\hline$<106 \mu \mathrm{m}$ & $86.88 \%$ & $94.97 \%$ & $0.41 \%$ & $7.45 \%$ \\
\hline$<75 \mu \mathrm{m}$ & $69.17 \%$ & $86.22 \%$ & $0.59 \%$ & $5.61 \%$ \\
\hline
\end{tabular}

The effect of increasing the purge time showed that the perceived results get coarser. However, the change of purge time had the smallest overall effect on the reported results. Finer particles were most influenced by increasing the purge time, with the highest percentage point decrease of $0.74 \%$.

Once again, these effects are all related to the particle entrainment mechanisms of a poly-dispersed two phase flow. The flow reacts to the pressure, flow rate, purge time as well as the angle of the probe. And different particle sizes react differently to these variations thus presenting a false (non-representative) flow to the laser eye for measurement.

\subsubsection{Point measurement depth effect}

The ability of the measurement device to capture a representative sample of the actual flow may also be analysed on a larger scale than that of the flow dynamics around the measuring tip and laser eye. The iso-kinetic sampler, for example, will extract PF from a pipe by performing a traverse of nearly the entire cross section of the pipe on an equal area basis (Fig. 22). This is to ensure confidence that the sample extracted is representative of the entire flow.

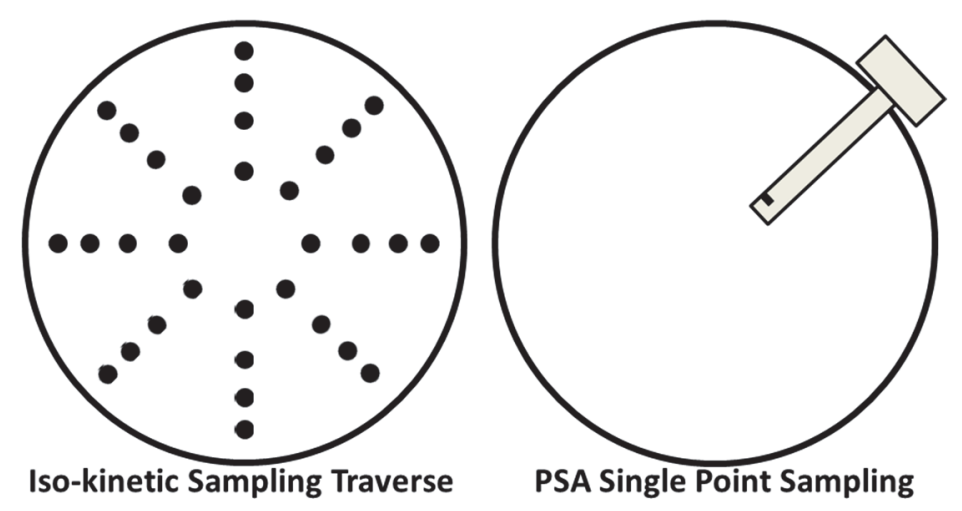

Fig. 22. Multi-point traverse vs. single point measurement

The PSA probe is not designed to perform a traverse as the probe length can achieve a maximum PF pipe penetration of $200 \mathrm{~mm}$ of a $457 \mathrm{~mm}$ internal diameter PF pipe. 
Table 8. Point measurement depth results

\begin{tabular}{|c|c|c|c|c|c|c|}
\hline $\begin{array}{c}@ 3 \mathrm{bar}, \\
10 \mathrm{~L} / \mathrm{m}, 4 \mathrm{~s}\end{array}$ & $\begin{array}{c}50 \\
\mathrm{~mm}\end{array}$ & $\begin{array}{c}100 \\
\mathrm{~mm}\end{array}$ & $\begin{array}{c}150 \\
\mathrm{~mm}\end{array}$ & $\begin{array}{c}200 \\
\mathrm{~mm}\end{array}$ & Max \% diff & $\begin{array}{c}\% \text { of } \\
\text { Window }\end{array}$ \\
\hline$\%<300 \mu \mathrm{m}$ & $99.92 \%$ & $99.89 \%$ & $99.90 \%$ & $99.86 \%$ & $0.06 \%$ & $7.50 \%$ \\
\hline$\%<150 \mu \mathrm{m}$ & $97.50 \%$ & $96.37 \%$ & $95.15 \%$ & $93.28 \%$ & $4.22 \%$ & $76.72 \%$ \\
\hline$\%<106 \mu \mathrm{m}$ & $88.75 \%$ & $85.77 \%$ & $82.87 \%$ & $78.42 \%$ & $10.33 \%$ & $98.38 \%$ \\
\hline$\%<75 \mu \mathrm{m}$ & $68.95 \%$ & $64.96 \%$ & $60.48 \%$ & $55.00 \%$ & $13.95 \%$ & $139.50 \%$ \\
\hline
\end{tabular}

The results of varying the depth of the point of measurement (Table 8) reveal an interesting phenomenon about the nature of the flow inside a PF pipe. As the PSA probe penetrates deeper into the pipe the probe reports pulverised fuel that is coarser in nature. This indicates that there is a higher concentration of coarse particles that travel at the centre of the vertically oriented PF pipe while the bulk of the finer particles tend to travel closer to the pipe walls. This trend has also been consistent amongst the PF pipes of different mills and even on mills of two different power stations that were tested.

The effect is largest at the smaller sieve sizes indicating a higher gradient of finer particles from the wall to the pipe centre. The change at the $300 \mu \mathrm{m}$ level is a mere 0.06 percentage points while at the 75 $\mu \mathrm{m}$ particles size the change is 13.96 percentage points (139.5\% of the window).

The test reveals that one may not assume a single point measurement to be representative of the entire flow. In order for this to be true one has to traverse the flow with the PSA probe and compare the individual point particle fineness results to the representative iso-kinetic sampling results. Only then can you determine that for a stable load and under those conditions, the closest matching PSA point result may pass as a single point measurement that is representative of the flow.

\subsection{Discussion}

The particle size analyser has shown itself in repeatability tests to be a very precise instrument. However many practical variables have been identified that do have adverse effects on the accuracy of the instrument. This makes it difficult to achieve a correct result (both high in precision and accuracy) as an off the shelf purchase. One needs to understand how measurement parameters will affect the results, and develop an operating and test procedure to alleviate any gross inaccuracies as well as accommodate for power station specific requirements such as correct PF pipe penetration. From the above investigation it can be seen that the correct set up of the purge air can be instrumental in achieving high accuracy. Gross error may be easily made if the angle of the measurement groove with respect to the PF flow has not been paid careful attention to. Finally the correct measurement depth should be determined during a commissioning phase and tests conducted in order to ensure that the point of measurement is a representative one. Further studies may be performed to determine the long term reliability of the instrument. Gradual degradation of the purging system or mechanical wear of the probe and lens shape may results in long term measurement drift. It is also uncertain how a change in the solid mass loading or mill load will affect the measurement results.

Once the PSA has been commissioned and all measurement parameters have been determined for the highest accuracy, the system may be used to determine and evaluate the quality of product being produced by the mill. Any gradual or drastic deviation from a given norm may then be attributed to various mill conditions such as grinding element wear and remaining life. The PSA may then be used in the determination of blocked classifiers, worn classifier blades, poor grinding performance, classifier blade angle adjustments, and historical tracking of milling performance, to name a few applications. 


\section{CONCLUSIONS}

In the business of energy transfer it is vital to supply the correct quantity of fuel input energy to the process. The device tasked to control this is the milling plant and the mass flow of coal that passes through it is the vital parameter to be controlled. Challenges facing the measurement of this parameter stem from the use of volumetric type screw feeders. These devices simply measure the rotational speed of the screw under the assumption that no change in coal density or coal moisture content had occurred since its last calibration. A cost effective solution, for older power stations where changing to gravimetric type feeders is unfeasible, would be to implement an on-line mill energy balance model to predict the coal flow rate in real time. The mill energy balance model developed herein can predict the coal flow rate through the mill in steady state within an average error of $2.33 \%$.

Apart from supplying the correct mass flow of coal, the other major role of the milling plant is to supply the correct particle fineness to the boiler. The ability to measure the product fineness of the milling plant in real time is long overdue. The particle size analyser, as a solution to such measurement, is a leap forward for milling plant engineers. On-line measurement and real time result reporting while setting up the mill is something that has not been possible with iso-kinetic sampling.

The limitation with iso-kinetic sampling, as performed currently, is that there is a long delay between the time of a test being performed and usable results being produced. There also exist aspects of the iso-kinetic process where human error can have an influence on the results, such as undersampling/over-sampling. The PSA on the other hand, almost completely removes human error while providing an instantaneous on-line and real-time result. This means it makes an ideal candidate for condition based monitoring and maintenance of the milling plant. However the uncertainties around the set-up and commissioning of the instrument as pointed out above should first be mitigated as far as possible.

Between the mill energy balance model and the particle size analyser, the two key parameters that determine the performance of a mill can be measured and monitored on-line and in real-time. Those key parameters are the quantity (coal mass flow) and quality (particle fineness) of the PF produced by the mill. Measuring and monitoring these parameters on-line is the first step towards 'condition monitoring' and furthermore 'condition based maintenance' of the milling plant.

\section{REFERENCES}

Aizu Y., Asakura T., 1987. Principles and development of spatial filtering velocimetry. Appl. Phys. B: Photophysics Laser Chem., B43, 4, 209-224.

Dodds J., Rasteiro G., Scarlett B., Weichert R., Williams R., 2004. From particle size analysis (PSA 1970) to particulate systems analysis (PSA 2003). Chem. Eng. Res. Des., 82, 1533-1540. DOI: 10.1205/cerd.82.12.1533.58040.

Eskom n.d., Company information overview. Available at: www.eskom.co.za/OurCompany/CompanyInformation/Pages/Company_Information.aspx

FPM S.A. n.d., Ball-ring mills. Available at: http://www.fpmsa.com/portal/pub/view/0x4764b?lang=en

Fan G.Q., Rees N.W., 1997. An intelligent expert system (KBOSS) for power plant coal mill supervision and control. Control Eng. Pract., 5, 101-108. DOI: 10.1016/S0967-0661(96)00213-4.

Hayden K.S., Park K., Curtis J.S., 2003. Effect of particle characteristics on particle pickup velocity. Powder Technol., 131, 7-14. DOI: 10.1016/S0032-5910(02)00135-3.

Incropera F.P., Dewitt D.P., Bergman T.L., Lavine A.S., 2007. Fundamentals of heat and mass transfer. $6^{\text {th }}$ Ed. John Wiley \& Sons.

JCGM 200:2012. International vocabulary of metrology - Basic and general concepts and associated terms (VIM). 3rd edition, JCGM. Available at: www.bipm.org/utils/common/documents/jcgm/JCGM_200_2012.pdf. 
Kitto, J.B., Stultz, S.C., 2005. Steam: It's generation and use, 41 st edition. The Babcock \& Wilcox Company.

Langston P.A., Burbidge A.S., Jones T.F., Simmons M.J.H. 2001. Particle and droplet size analysis from chord measurements using Bayes' theorem. Powder Technol., 116, 33-42. DOI: 10.1016/S0032-5910(00)00359-4.

Makokha A.B., Moys M.H., Couvas C., Muumbo A.M., 2009. Steady state inferential modeling of temperature and pressure in an air-swept coal pulverizing ball mill. Powder Technol., 192, 260-267. DOI: 10.1016/S00325910(00)00359-4.

Niemczyk P., Bendtsen D.J., Ravn P.A., Andersen P., Pedersen S.T., 2012. Derivation and validation of a coal mill model for control. Control Eng. Pract., 20, 519-530. DOI: 10.1016/j.conengprac.2012.01.006.

Odgaard P.F., Mataji B., 2007. Fault detection in coal mills used in power plants, In: Westwick D. (Ed.), Power Plants and Power Systems Control 2006. Elsevier Science Ltd, Oxford, 177-182.

Parsum, 2011. In line particle probe operating manual/Hardware Manual.

Petrak D., 2002. Simultaneous measurement of particle size and particle velocity by the spatial filtering technique. Part. Part. Syst. Char. , 19, 391-400. DOI: 10.1002/ppsc.200290002.

Rees N.W., Fan G.Q., 2003. Thermal power plant simulation and control, In: Flynn D. (Ed.), Thermal power plant simulation and control: Chapter 3. Modelling and control of pulverized fuel coal mills. Institution of Electrical Engineers, 63-99.

Sonntag R., Borgnakke C., Wylen G.J., 1998. Fundamentals of classical thermodynamics. $5^{\text {th }}$ ed. John Wiley \& Sons.

Wei J.L., Wang J., Wu Q.U., 2007. Development of a multisegmented coal mill model using an evolutionary computation technique. IEEE Trans. Energy Convers., 22, 718-727. DOI: 10.1109/TEC.2007.895459.

Jerez S.B., Zhang Y., McClure J.W., Jacobson L., Heber A., Hoff S., Koziel J., Beasley D., 2006. Comparison of measured total suspended particulate matter concentrations using tapered element oscillating microbalance and a total suspended particulate sampler. J. Air Waste Manage. Assoc., 56, 261-270. DOI: 10.1080/10473289.2006.10464460.

JCGM 100:2008, 2008. Evaluation of measurement data - Guide to the expression of uncertainty in measurement. $1^{\text {st }}$ ed. Available at: www.iso.org/sites/JCGM/GUM/JCGM100/C045315e-html/C045315e.html.

Received 11 March 2015

Received in revised form 16 February 2016

Accepted 20 February 2016 